Science \& Engineering A

Manuscript Number: MSEA-D-15-01949R1

Title: Residual stress within nanoscale metallic multilayer systems during thermal cycling

Article Type: Research Paper

Keywords: Copper-Niobium; Thin films; Nanoscale metallic multilayers; Thermomechanical processing; Residual stresses; Thermal expansion mismatch

Corresponding Author: Dr. David Ross Economy, Ph.D.

Corresponding Author's Institution:

First Author: David Ross Economy, Ph.D.

Order of Authors: David Ross Economy, Ph.D.; Megan J Cordill, Ph.D.; E. Andrew Payzant, Ph.D.; Marian S Kennedy, Ph.D.

Abstract: Projected applications for nanoscale metallic multilayers will include wide temperature ranges. Since film residual stress has been known to alter system reliability, stress development within new film structures with high interfacial densities should be characterized to identify potential long-term performance barriers. To understand factors contributing to thermal stress evolution within nanoscale metallic multilayers, stress in $\mathrm{Cu} / \mathrm{Nb}$ systems adhered to Si substrates was calculated from curvature measurements collected during cycling between $25{ }^{\circ} \mathrm{C}$ and $400{ }^{\circ} \mathrm{C}$. Additionally, stress within each type of component layers was calculated from shifts in the primary peak position from insitu heated $\mathrm{X}$-ray diffraction. The effects of both film architecture (layer thickness) and layer order in metallic multilayers were tracked and compared with monolithic $\mathrm{Cu}$ and $\mathrm{Nb}$ films (1 $\mu \mathrm{m}$ total thickness). Analysis indicated that the thermoelastic slope of nanoscale metallic multilayer films (with $20 \mathrm{~nm}$ and $100 \mathrm{~nm}$ individual layer thicknesses) depends on thermal expansion mismatch, elastic modulus of the components, and also interfacial density. The layer thickness (i.e. interfacial density) affected thermoelastic slope magnitude $\left(-1.23 \pm 0.09 \mathrm{MPa} /{ }^{\circ} \mathrm{C}\right.$ for $20 \mathrm{~nm} \mathrm{Cu} / \mathrm{Nb}$ vs. $-0.89 \pm 0.03 \mathrm{MPa} /{ }^{\circ} \mathrm{C}$ for $\left.100 \mathrm{~nm} \mathrm{Cu} / \mathrm{Nb}\right)$ while layer order had minimal impact on stress responses after the initial thermal cycle ($0.82 \pm 0.07 \mathrm{MPa} /{ }^{\circ} \mathrm{C}$ for $\left.100 \mathrm{~nm} \mathrm{Cu} / \mathrm{Nb}\right)$. When comparing stress responses of monolithic $\mathrm{Cu}$ and $\mathrm{Nb}$ films to those of the $\mathrm{Cu} / \mathrm{Nb}$ systems, the nanoscale metallic multilayers show a similar increase in stress above $200{ }^{\circ} \mathrm{C}$ to the Nb monolithic films, indicating that Nb components play a larger role in stress development than $\mathrm{Cu}$. Phase specific stress calculations (Cu vs. Nb) from X-ray diffraction peak shifts in $20 \mathrm{~nm} \mathrm{Cu/Nb}$ collected during heating reveal that the component layers within a multilayer film respond similarly to their monolithic counterparts. 
September 1, 2015

Professor Nik Chawla

Editor, Materials Science and Engineering A

Arizona State University

Engineering Research Center \#285

551 E Tyler Mall

Tempe, AZ 85281

nchawla@asu.edu

RE: Revisions to Manuscript MSEA-D-15-01949

Dear Editor Chawla,

We would like to sincerely thank you for sharing the reviewer comments on our manuscript MSEA-D-15-01949 with us, they were very insightful and helped us to further strengthen the manuscript. Based on those thoughtful suggestions we have made the following revisions that are noted below and are highlighted in the manuscript itself. We greatly appreciate the opportunity to contribute this revised version for publication in MSEa.

Thank you very much for your consideration and we look forward to seeing this work in press.

Sincerely, D. Ross Economy 
Comments from Reviewers:

Comment: This manuscript is a well-carried out experimental investigation into the evolution of internal stresses in $\mathrm{Cu}-\mathrm{Nb}$ nanoscale multilayers using a combination of in-situ stress measurement techniques. It is appropriate for publication in MSEA, however, a few minor corrections need to be addressed before it can be further considered for publication. These are listed below:

1.) It would be helpful to add some specific results to the abstract, such as layer thicknesses, internal stress values, etc. It is quite general as it stands now.

Author response to comment 1: Added details in parentheses "Analysis indicated that the thermoelastic slope of nanoscale metallic multilayer films (with $20 \mathrm{~nm}$ and $100 \mathrm{~nm}$ individual layer thicknesses) depends on thermal expansion mismatch, elastic modulus of the components, and also interfacial density. The layer thickness (i.e. interfacial density) affected thermoelastic slope magnitude $\left(-1.23 \pm 0.09 \mathrm{MPa} /{ }^{\circ} \mathrm{C}\right.$ for $20 \mathrm{~nm} \mathrm{Cu} / \mathrm{Nb}$ vs. $-0.89 \pm 0.03 \mathrm{MPa} /{ }^{\circ} \mathrm{C}$ for $100 \mathrm{~nm}$ $\mathrm{Cu} / \mathrm{Nb}$ ) while layer order had minimal impact on stress responses after the initial thermal cycle ($0.82 \pm 0.07 \mathrm{MPa} /{ }^{\circ} \mathrm{C}$ for $\left.100 \mathrm{~nm} \mathrm{Cu} / \mathrm{Nb}\right) . "$ to abstract and some other minor details.

2.) The calculation carried out using equation 1 is not exactly clear to me. How is Si accounted for? In this equation, it seems that it is only for the film. For the mismatch in delta alpha, is this the mismatch between film and substrate in this case, or $\mathrm{Cu}$ and $\mathrm{Nb}$ ? Please clarify the explanation of how the calculation was carried out.

Author response to comment 2: Clarified wording on page 4 around Eq. 1. "Keller et al. has described thermoelastic slope of a film, $m$, in monolithic film systems on a substrate as:

$$
m=\left(\frac{E_{f}}{1-v_{f}}\right) \Delta \alpha
$$

where it depends on elastic components: $E_{f}$, elastic modulus of the film and Poisson's ratio of the film, $v_{f}$, and thermal expansion mismatch between the film and substrate, $\Delta \alpha$ [31]. Based on predictions using Eq. (1) $\mathrm{Cu} / \mathrm{Nb}$ should have an estimated thermoelastic slope of $-1.8 \mathrm{MPa} /{ }^{\circ} \mathrm{C}$ based on literature values of $\mathrm{CTE}$ for $\mathrm{Cu}, \mathrm{Nb}$, and $\mathrm{Si}$ (using the difference between $\mathrm{Si}$ and a combined mean value for both $\mathrm{Cu}$ and $\mathrm{Nb}$ ) [40,41], approximate elastic modulus from nanoindentation $(125 \mathrm{GPa})$, and an assumed Poisson's ratio $(v \approx 0.37$, [47])."

3.) On page 5, What specifically are the authors defining as "stresses associated with the layer interfaces"? It is not clear if these are due to lattice mismatch at the atomic level, stress gradients due to thermal expansion coefficient mismatch, etc. This paragraph should be made more specific to elucidate the points the authors intend to make. Likewise, some more introduction into the differences between "localized stress" and composite stress, as mentioned earlier, would be helpful. It would be more correct to call the strains/stresses measured via XRD as "phase specific strains/stresses", as there is no spatial correlation within a given layer.

Author response to comment 3: Added "These stresses have been attributed to local CTE variation [30] and the surface energies assiociated with the interface [34]." to page 5. Also clarified references to local stress as phase specific, on page 5 "This complimentary approach to examining stress response allowed for the determination of differences between the phase 
specific stress and the composite stress in the $\mathrm{Cu} / \mathrm{Nb} \mathrm{NMM}$ architecture (phase specific: $\mathrm{Cu}$ or $\mathrm{Nb}$ vs. composite: $\mathrm{Cu}$ and $\mathrm{Nb}) . "$ and elsewhere in the manuscript.

4.) How is biaxial stress as calculated in the manuscript similar to or different from composite stress from Stoney's equation, which is typically only calculated in one direction?

Author response to comment 4: After reading the reviewers comment on the biaxial stress aspect in relation to Stoney's equation, we returned the film stress determination literature. The authors noted that in more recent discussions of the curvature methods of estimating film stress, if a two-dimensional measurement is used (representing the biaxial case), then Poisson's ratio should be used in the stress calculations. Stoney's equation was initially used to estimate stress in a long narrow bending beam (one-dimensional curvature measurement), however it has been more commonly applied in current contexts to the developing stress of thin films on circular silicon substrates (two-dimensional curvature measurement). Per the suggestions of Ohring's Materials Science of Thin Films (pp. 728-730, Copyright 2002, ref. 19), equation 2 in the manuscript was updated accordingly "In this study, biaxial film stress was approximated by measuring changes in substrate curvature and calculated using a modified form of Stoney's equation $[19,39]$ :

$$
\sigma_{f}=\frac{M_{S} t_{S}^{2}}{6\left(1-v_{s}\right) t_{f}}\left(\frac{1}{R_{\text {final }}}-\frac{1}{R_{\text {initial }}}\right)
$$

where $M_{s}$ is biaxial elastic modulus of substrate [(100) $\mathrm{Si}$ for the purposes of this study], $t_{s}$ is the substrate thickness, $t_{f}$ is film thickness, $v_{s}$ is the Poisson ratio of the substrate (0.28 for Si [38]) and $R_{\text {final }}$ and $R_{\text {initial }}$ are the final and initial radii of curvature of the substrate respectively." on page 7 and the resulting data in the rest of the manuscript and the figures based on those data were all updated to reflect this change.

5.) When were the monolithic samples deposited? Were the $2 / 2013$ sample stresses measured again after "aging"?

Author response to comment 5: Added "It is important to note that stresses in the samples deposited in 2/2013 were measured immediately following deposition. Since room temperature stress relief (up to 25\%) has been observed for Mo/Si multilayer systems over a period of six months, these values may be overestimates [30]. For reference, the monolithic film systems and most of the NMM films were deposited just prior to the stress examination (4/2014)." on page 11 with discussion of initial stress values.

6.) Please comment on the difference in homologous melting temperature between $\mathrm{Cu}$ and $\mathrm{Nb}$, and how that could affect the differences in hysteresis, stress evolution, etc. It is mentioned in terms of grain growth on page 25 , but could have other effects as the $\mathrm{Cu}$ phase softens considerably relative to the $\mathrm{Nb}$ during testing.

Author response to comment 6: Added: "It is hypothesized that the overall maximum stress achievable in the NMM systems at high temperatures is limited by the high-temperature yield strength of the $\mathrm{Cu}$ layers. Other researchers have measured the hot-hardness of $\mathrm{Cu}$ to be below 1 $\mathrm{GPa}$ at $400{ }^{\circ} \mathrm{C}$ [48]. The decreased yield strength of $\mathrm{Cu}$ layers combined with the high stress of the $\mathrm{Nb}$ layers would indicate that yielding may occur due to the stresses measured in NMMs at high temperature. However, this would be limited to the $\mathrm{Cu}$ components of the NMMs as $\mathrm{Nb}$ 
has a much greater melting temperature $\left[1085{ }^{\circ} \mathrm{C}(1358 \mathrm{~K})\right.$ and $2469{ }^{\circ} \mathrm{C}(2742 \mathrm{~K})$ for $\mathrm{Cu}$ and $\mathrm{Nb}$, respectively]." to page 19 to discuss the relative differences in softening between $\mathrm{Cu}$ and $\mathrm{Nb}$. Also added "The overall difference in magnitude of stress might be expected due to the large difference in homologous temperature ranges used, a factor of the different melting temperatures of the films; $\mathrm{Cu}$, a relatively low melting metal and $\mathrm{Nb}$, which is a refractory metal $\left[1085{ }^{\circ} \mathrm{C}\right.$ $(1358 \mathrm{~K})$ and $2469{ }^{\circ} \mathrm{C}(2742 \mathrm{~K})$, respectively]." on page 15 following the introduction of monolithic stress results.

7.) On page 18 , it might be worth mentioning that a brief heat treatment after deposition can negate the initial stress conditions and aging effects, which could be a useful post-deposition treatment for applications.

Author response to comment 7: Added "Additionally, some researchers have mitigated the first cycle effect by short annealing steps prior to their thermal cycling stress measurements [20]." to page 18.

8.) On page 22 , the authors should comment on the structural differences between $\mathrm{Cu} / \mathrm{Ni}$ and $\mathrm{Cu} / \mathrm{Nb}$, such as the relative difference in coherency, heat of mixing, and elastic modulus in relation to their internal stress evolution during the annealing process. Specifically, what about the difference in misfit dislocation structure in $\mathrm{Cu} / \mathrm{Ni}$, which is nearly coherent, and $\mathrm{Cu} / \mathrm{Nb}$, where misfit is larger?

Author response to comment 8: Added "It is noted that there are other considerable structural differences between the $\mathrm{Cu} / \mathrm{Nb} \mathrm{NMM}$ systems examined in the present study and the $\mathrm{Cu} / \mathrm{Ni}$ examined by Gram et al. [33] and $\mathrm{Mo} / \mathrm{Si}$ examined by Windt [30] including interfacial coherency (incoherent for $\mathrm{Cu} / \mathrm{Nb}$ and nearly coherent for $\mathrm{Cu} / \mathrm{Ni}$ ) and elastic modulus mismatch. The impact of elastic modulus can be seen in the initial approximation of thermoelastic slope (Eq. 1) where greater values result in larger stresses [31]. Further, the interfacial coherency is likely to impact the development of the interfacial stresses that have been attributed to the change in layer thickness, but the full impact is not yet known." to page 22 .

9.) In figure 8 , what is the error/repeatability of these measurements relative to the hysteresis that the authors point out? It seems that the hysteresis is relatively small.

Author response to comment 9: In order to discuss repeatability of measurements, the following comments were added to the manuscript "Repeatability of the cyclic stress behaviors were ascertained by performing these tests two to three times on each sample type." on page 9 and "These hystereses, although small, can be repeatedly observed as these stress profiles were measured two to three times for each condition." was added on page 24.

10.) On page 25 , the values given for "half the melting point" should be with respect to homologous temperature, that is, for copper half the melting point is $(273+1085) / 2=679 \mathrm{~K}=406 \mathrm{C}$. These tests are very close to half of Tm, which further supports why grain growth was observed in the copper phase. 
Author response to comment 10: We have revised the references to the melting temperature to reflect the homologous temperature as suggested. Now the section on page 25 reads "This is to be expected considering the melting temperatures of $\mathrm{Cu}$ and $\mathrm{Nb}, 1085{ }^{\circ} \mathrm{C}(1358 \mathrm{~K})$ and $2469{ }^{\circ} \mathrm{C}$ $(2742 \mathrm{~K})$ respectively. The temperature associated with grain growth in bulk metals is often assumed to be approximately half of the melting temperature $\left[406{ }^{\circ} \mathrm{C}(679 \mathrm{~K})\right.$ and $1098{ }^{\circ} \mathrm{C}(1371$ $\mathrm{K})$ for $\mathrm{Cu}$ and $\mathrm{Nb}$, respectively]." 
For Submission to Materials Science and Engineering A

\title{
Residual stress within nanoscale metallic multilayer systems during thermal cycling
}

\author{
D. R. Economy ${ }^{\mathrm{a}, *}$, M. J. Cordill ${ }^{\mathrm{b}}$, E. A. Payzant ${ }^{\mathrm{c}}$, M. S. Kennedy ${ }^{\mathrm{a}, \mathrm{d}}$ \\ ${ }^{a}$ Department of Materials Science and Engineering, Clemson University, Clemson, SC 29634, \\ USA \\ ${ }^{\mathrm{b}}$ Erich Schmid Institute, Austrian Academy of Sciences and Department of Materialphysik, \\ Montanuniversitaet Leoben, Leoben 8700, Austria \\ ${ }^{\mathrm{c}}$ Center for Nanophase Materials Sciences, Oak Ridge National Laboratory, Oak Ridge, TN \\ 37831, USA \\ ${ }^{\mathrm{d}}$ Center for Optical Materials Science and Engineering Technologies (COMSET), Clemson \\ University, Clemson, SC 29634, USA \\ * Corresponding author. Tel.: +1 864.722.2107. \\ E-mail address: deconom@g.clemson.edu (D. R. Economy).
}

\section{Abstract}

Projected applications for nanoscale metallic multilayers will include wide temperature ranges. Since film residual stress has been known to alter system reliability, stress development within new film structures with high interfacial densities should be characterized to identify potential long-term performance barriers. To understand factors contributing to thermal stress evolution within nanoscale metallic multilayers, stress in $\mathrm{Cu} / \mathrm{Nb}$ systems adhered to $\mathrm{Si}$ substrates was calculated from curvature measurements collected during cycling between $25^{\circ} \mathrm{C}$ and $400{ }^{\circ} \mathrm{C}$. Additionally, stress within each type of component layers was calculated from shifts in the primary peak position from in-situ heated X-ray diffraction. The effects of both film architecture (layer thickness) and layer order in metallic multilayers were tracked and compared with monolithic $\mathrm{Cu}$ and $\mathrm{Nb}$ films (1 $\mu \mathrm{m}$ total thickness). Analysis indicated that the thermoelastic slope of nanoscale metallic multilayer films (with $20 \mathrm{~nm}$ and $100 \mathrm{~nm}$ individual layer thicknesses) depends on thermal expansion mismatch, elastic modulus of the components, and also interfacial density. The layer thickness (i.e. interfacial density) affected thermoelastic slope magnitude $\left(-1.23 \pm 0.09 \mathrm{MPa} /{ }^{\circ} \mathrm{C}\right.$ for $20 \mathrm{~nm} \mathrm{Cu} / \mathrm{Nb}$ vs. $-0.89 \pm 0.03 \mathrm{MPa} /{ }^{\circ} \mathrm{C}$ for $\left.100 \mathrm{~nm} \mathrm{Cu} / \mathrm{Nb}\right)$ while layer order had minimal impact on stress responses after the initial thermal cycle $(-0.82 \pm$ 
For Submission to Materials Science and Engineering A

$0.07 \mathrm{MPa} /{ }^{\circ} \mathrm{C}$ for $100 \mathrm{~nm} \mathrm{Cu} / \mathrm{Nb}$ ). When comparing stress responses of monolithic $\mathrm{Cu}$ and $\mathrm{Nb}$ films to those of the $\mathrm{Cu} / \mathrm{Nb}$ systems, the nanoscale metallic multilayers show a similar increase in stress above $200{ }^{\circ} \mathrm{C}$ to the $\mathrm{Nb}$ monolithic films, indicating that $\mathrm{Nb}$ components play a larger role in stress development than $\mathrm{Cu}$. Phase specific stress calculations ( $\mathrm{Cu}$ vs. $\mathrm{Nb}$ ) from $\mathrm{X}$-ray diffraction peak shifts in $20 \mathrm{~nm} \mathrm{Cu} / \mathrm{Nb}$ collected during heating reveal that the component layers within a multilayer film respond similarly to their monolithic counterparts.

Keywords: Copper-Niobium, Thin films, Nanoscale metallic multilayers, Thermomechanical processing, Residual stresses, Thermal expansion mismatch

\section{Introduction}

To enhance mechanical properties of thin films, research groups have started creating synthetic two-dimensional structures within films by selective deposition of metallic films. One of these such structures that have become prevalent recently are nanoscale metallic multilayers (NMMs). NMMs are composed of alternating metallic layers with nanometer-level $(<100 \mathrm{~nm})$ individual layer thicknesses that have shown superior strength [1-3], radiation damage resistance [4-6], and wear-resistance $[7,8]$ when compared to their monolithic counterparts. These types of layered systems are referred to in many different manners by various researchers including NMMs, nanolaminates, multilayers, herringbone structures, nanoheterostructures, et cetera; however, many of the terms are synonymous. For the purposes of this work, these systems will be referred to as NMMs. In some cases, researchers have observed that these film systems have undergone both microstructural and mechanical instability during heating [9-12]. These 
microstructural and mechanical instabilities in NMM systems have been linked to residual stresses imposed by the substrate during thermal cycling [9-12].

Residual stress can be a significant factor in the response of a material to external stimuli, most notably the magnitudes of diffusion [13,14], deformation [15-17], and optical transmission [18]. This type of stress has been observed in both thin films and bulk metals. In bulk metals, the magnitude of residual stress is often below that of the yield stress level [19]. However, in thin-film systems, residual stresses have been observed to readily exceed $1 \mathrm{GPa}$ in either tension or compression [19]. Intrinsic sources of residual stress in thin films include those due to the system's microstructure, or those originating from defects during film deposition [19]. Extrinsic sources of stress in thin-film systems can include those due to thermal expansion mismatches between the substrate and film constituent materials [19]. When researchers compare the stresses calculated in monolithic films during thermal cycles, they often observe a deviation between the stress hysteresis of the first and subsequent thermal cycles [20-22]. After the initial relief of intrinsic stresses from deposition, the primary source of stress within films during thermal cycling is typically assumed to arise from thermal expansion mismatch between the film and substrate. This study seeks to examine the development of residual stress in $\mathrm{NMM} \mathrm{Cu/Nb}$ films adhered to Si during thermal cycling due to the role of stress on the microstructural instability [9-12]. This work is necessary to further understand the development of residual stresses in NMM film systems to foster their usage in practical settings such as high-strength coatings in extreme temperature environments for energy and defense applications [23].

$\mathrm{Cu} / \mathrm{Nb}$ was chosen as a model system in this study due to its frequency in the literature [2,9,24-27] and because the constituent materials $(\mathrm{Cu}$ and $\mathrm{Nb})$ do not form intermetallic compounds with one another $[23,28]$. To understand the thermal stress response of a composite 
film system, it is necessary to understand the constituents by themselves $[29,30]$. The thermal response of copper films has been studied extensively due to its importance in the microelectronics industry [20,21,31,32]. Thermal stress response in Nb films, however, has not been examined in the literature.

A key parameter to understanding the thermal stress development of films is the elastic (linear) slope of the stress as a function of temperature that can typically be found on cooling, which is known as the thermoelastic slope [22]. This parameter gives an indication of how much stress is being developed from changes in temperature with a greater magnitude indicating greater stress. Keller et al. has described thermoelastic slope of a film, $m$, in monolithic film systems on a substrate as:

$$
m=\left(\frac{E_{f}}{1-v_{f}}\right) \Delta \alpha
$$

where it depends on elastic components: $E_{f}$, elastic modulus of the film and Poisson's ratio of the film, $v_{f}$, and thermal expansion mismatch between the film and substrate, $\Delta \alpha[31]$. Based on predictions using Eq. (1) $\mathrm{Cu} / \mathrm{Nb}$ should have an estimated thermoelastic slope of $-1.8 \mathrm{MPa} /{ }^{\circ} \mathrm{C}$ based on literature values of $\mathrm{CTE}$ for $\mathrm{Cu}, \mathrm{Nb}$, and $\mathrm{Si}$ (using the difference between $\mathrm{Si}$ and a combined mean value for both $\mathrm{Cu}$ and $\mathrm{Nb}$ ) [33,34], approximate elastic modulus from nanoindentation $(125 \mathrm{GPa})$, and an assumed Poisson's ratio $(v \approx 0.37,[35])$.

Only two studies have been found that sought to examine the thermal stress progression for nanoscale multilayer systems $[30,36]$. Windt studied the thermal stress response of multilayer films with sub-10 nm individual layers of Mo, W, Si, and C (also on Si substrates) to examine the role of nanoscale multilayer architecture on thermal stress development [30]. Windt's study did not examine how varying the magnitudes of layer thickness might impact stress, but solely focused on characterizing the difference between sub-10 nm individual layer thickness ( $1 \mathrm{~nm}$ to 
$5 \mathrm{~nm}$ ) multilayer films [30]. Similarly, Gram et al. examined the stress responses of $11 \mathrm{~nm}$ and

$21 \mathrm{~nm} \mathrm{Cu} / \mathrm{Ni} \mathrm{NMMs}$ during heating [36]. In Windt's study, it was observed that the varying architectures in either a net tensile or net compressive stress after heating depended on individual layer thickness. This variation in stress response was attributed to the role of interfacial stresses in the systems [30], which are defined as those associated with the layer interfaces (one layer to another) [37]. These stresses have been attributed to local CTE variation [30] and the surface energies assiociated with the interface [37]. The role of interfacial stresses aside from the film/substrate interface in monolithic films and macro-multilayers is negligible due to low interfacial density, but could become appreciable for nanoscale layer thicknesses. Gram et al. identified that there is a separate stress response in the component layers $(\mathrm{Cu}$ versus $\mathrm{Ni})$, as was shown with in-situ heated XRD, and that the thicker $21 \mathrm{~nm}$ layered system showed greater deviation from the predicted thermoelastic slope [36].

In this study stress was approximated in two separate contexts; first to estimate the residual stress developed during deposition (how the substrate changes before and after the film is initially deposited) to serve as starting values for the study. Second, the curvature was monitored continuously throughout a thermal cycle in two different in-situ systems, substrate curvature and $\mathrm{XRD}$, to show the progression of thermal stress during heating and cooling. This complimentary approach to examining stress response allowed for the determination of differences between the phase specific stress and the composite stress in the $\mathrm{Cu} / \mathrm{Nb} \mathrm{NMM}$ architecture (phase specific: $\mathrm{Cu}$ or $\mathrm{Nb}$ vs. composite: $\mathrm{Cu}$ and $\mathrm{Nb}$ ).

\section{Experimental methods}




\subsection{Fabrication of thin film systems}

$\mathrm{Cu} / \mathrm{Nb} \mathrm{NMM}$ and monolithic $\mathrm{Cu}$ and $\mathrm{Nb}$ films were deposited to examine the influence of film architecture and geometry on residual stress development during thermal cycling. All films were deposited on (100) Si substrates (350-400 $\mu \mathrm{m}$ thickness) using a Kurt J. Lesker sputter deposition system using a process detailed previously [9]. The deposition rates obtained were $4.0 \mathrm{~nm} / \mathrm{min}$ for $\mathrm{Cu}$ and $2.9 \mathrm{~nm} / \mathrm{min}$ for $\mathrm{Nb}$. Six types of samples were deposited for this study, $20 \mathrm{~nm} \mathrm{Cu} / \mathrm{Nb}, 20 \mathrm{~nm} \mathrm{Nb} / \mathrm{Cu}$ (50 total layers), $100 \mathrm{~nm} \mathrm{Cu} / \mathrm{Nb}, 100 \mathrm{~nm} \mathrm{Nb} / \mathrm{Cu}$ (10 total layers), as well as monolithic $\mathrm{Cu}$ and $\mathrm{Nb}$ films. In all films the total thickness was kept constant at $1 \mu \mathrm{m}$. The two different notations for the NMM systems $(\mathrm{Cu} / \mathrm{Nb}$ and $\mathrm{Nb} / \mathrm{Cu})$ indicate the layer order (geometry) with $\mathrm{Cu} / \mathrm{Nb}$ having the $\mathrm{Cu}$ layer deposited first and $\mathrm{Nb}$ layer deposited subsequently, and the reverse for the $\mathrm{Nb} / \mathrm{Cu}$ samples. The two different geometries were used to examine the influence of the base layer on the stress development. Additionally, the monolithic $\mathrm{Cu}$ film contained an $\mathrm{Nb}$ adhesion layer (approximate thickness: $5 \mathrm{~nm}$ ). A matrix of the samples produced for this study is included in Table 1.

\section{Table 1}

Film systems produced for studying the effects of architecture and geometry on performance during and after thermal cycling.

\begin{tabular}{cccc}
\hline & \multicolumn{3}{c}{ Layer Geometry } \\
\cline { 2 - 4 } & $\mathrm{Cu} / \mathrm{Nb} \mathrm{NMM} \mathrm{Systems}$ & $\mathrm{Nb} / \mathrm{Cu} \mathrm{NMM}$ Systems & Monolithic Systems \\
\hline Layer & $20 \mathrm{~nm} \mathrm{Cu} / \mathrm{Nb}$ & $20 \mathrm{~nm} \mathrm{Nb} / \mathrm{Cu}$ & $1 \mu \mathrm{m} \mathrm{Cu}$ \\
Architecture & $100 \mathrm{~nm} \mathrm{Cu} / \mathrm{Nb}$ & $100 \mathrm{~nm} \mathrm{Nb} / \mathrm{Cu}$ & $1 \mu \mathrm{m} \mathrm{Nb}$ \\
\hline \multicolumn{3}{c}{ Total thickness of each system was $1 \mu \mathrm{m}$} \\
\hline
\end{tabular}

\subsection{Characterization methods}

As-deposited film residual stress (due to deposition parameters) was calculated using the changes in substrate curvature before and after film deposition as measured by stylus 
For Submission to Materials Science and Engineering A

profilometry (Veeco Dektak ${ }^{3}$ ). This curvature was measured using $20 \mathrm{~mm}$ line scans, with seven radial measurements taken per sample both before and after deposition. These measurements were then used along with the constraints imposed by the Si substrate [38] to calculate residual stress using Stoney's equation [39].

Additionally, initial hardness was calculated from nanoindentation load-displacement measurements with a three-sided diamond Berkovich indentation probe $\left(E_{\text {Diamond }}: 1140 \mathrm{GPa}\right.$, $v_{\text {Diamond }} 0.07$ [15]). Each sample was indented a minimum of 24 times, four indents each at six maximum depths between $100 \mathrm{~nm}$ and $75 \mathrm{~nm}$, using the displacement-controlled indentation mode on a Hysitron Triboscope system. Nanoindentation data analysis was performed in accordance with the Oliver-Pharr method [40]. The Triboscope system was calibrated using fused quartz immediately prior to testing $\left(E_{\mathrm{R}}: 69.6 \mathrm{GPa}, H: \approx 9 \mathrm{GPa}\right)[15]$.

Mechanical, microstructural (morphology and grain growth), and chemical (formation of new phase) changes were characterized following thermal cycling using nanoindentation, electron backscatter diffraction (EBSD), atomic force microscopy (AFM), and X-ray diffraction (XRD). EBSD was performed using an EDAX Inc. system, which was integrated into a LEO 1525 fieldemission-gun scanning electron microscope (SEM). The in-plane grain size of the top film layers were calculated by the line intercept method using one-micrometer square images of each sample taken by a Digital Instruments Dimension AFM in tapping mode. Additional structural and chemical characterization was carried out using XRD on a Rigaku SmartLab four-circle diffractometer. 
For Submission to Materials Science and Engineering A

\subsection{Stress approximation in thin films}

In this study, biaxial film stress was approximated by measuring changes in substrate curvature and calculated using a modified form of Stoney's equation [19,39]:

$$
\sigma_{f}=\frac{M_{s} t_{s}^{2}}{6\left(1-v_{s}\right) t_{f}}\left(\frac{1}{R_{\text {final }}}-\frac{1}{R_{\text {initial }}}\right)
$$

where $M_{s}$ is biaxial elastic modulus of substrate [(100) Si for the purposes of this study], $t_{s}$ is the substrate thickness, $t_{f}$ is film thickness, $v_{s}$ is the Poisson ratio of the substrate (0.28 for Si [38]) and $R_{\text {final }}$ and $R_{\text {initial }}$ are the final and initial radii of curvature of the substrate respectively. This relation uses a thin film, thick substrate approximation $\left(t_{f}<t_{s}\right)$, practically assuming that the curvature change is governed solely by the mechanical properties of the substrate as can be seen in Eq. (2).

\subsection{In-situ measurement of residual stress during thermal cycling}

The in-situ substrate curvature measurement system used in this study is a custom-built instrument at the Erich Schmid Institute of Materials Science in Leoben, Austria. The system is comprised of a vacuum chamber, an Edwards turbomolecular pump, a ceramic resistance heater, and a kSA Multi-beam Optical Sensor (MOS) in-situ stress monitoring system. The kSA MOS system utilizes a series of parallel mirrors (etalons) to split the laser beam into 16 diffracted spots into a four $\times$ four-spot matrix allowing curvature measurement in both horizontal and vertical directions. The kSA MOS system was calibrated using reference mirrors [an optical flat and a concave mirror (radius: $10 \mathrm{~m}$ ) from Edmund Optics].

Samples were subjected to a temperature cycle between $25{ }^{\circ} \mathrm{C}$ and $400{ }^{\circ} \mathrm{C}$ using a heating rate of $10{ }^{\circ} \mathrm{C} / \mathrm{min}$ and a minimum vacuum of $7.5 \times 10^{-5}$ Torr. Upon reaching the maximum temperature, the samples were held at $400{ }^{\circ} \mathrm{C}$ for 40 minutes, then allowed to cool to room 
temperature. The system did not include any means for active cooling. The cooling rate was not controlled and resulted in an average cooling rate of $\approx 6.9{ }^{\circ} \mathrm{C} / \mathrm{min}$. Each individual, single-cycle test took approximately three hours in total. A maximum temperature of $400{ }^{\circ} \mathrm{C}$ was chosen for consistency with previous work studying $\mathrm{Cu} / \mathrm{Nb} \mathrm{NMM}$ systems adhered to silicon substrates [9]. Additional three-cycle tests were performed with an identical first cycle to the single cycle tests; the following two cycles were similar but isothermal holds were reduced to five minutes and the minimum temperature reached between cycles was $40{ }^{\circ} \mathrm{C}$. It has been established that the primary stress responses that occur during a deposited film's first heating cycle are irreversible, often due to the relief of defects formed during deposition and microstructural evolution [20,21]. Thus, the stress behaviors in the film on the first cycle are not indicative of future stress evolution. As such, it is necessary to study the stress progression in films through multiple cycles to examine both the initial changes as well as the stress behavior after those initial fluctuations have occurred. Thermal cycling stress tests were conducted under vacuum $(<$ $7.5 \times 10^{-5}$ Torr). A representative thermal and stress profile for a three-cycle test can be seen in Fig. 1. Repeatability of the cyclic stress behaviors were ascertained by performing these tests two to three times on each sample type.

\section{A)}

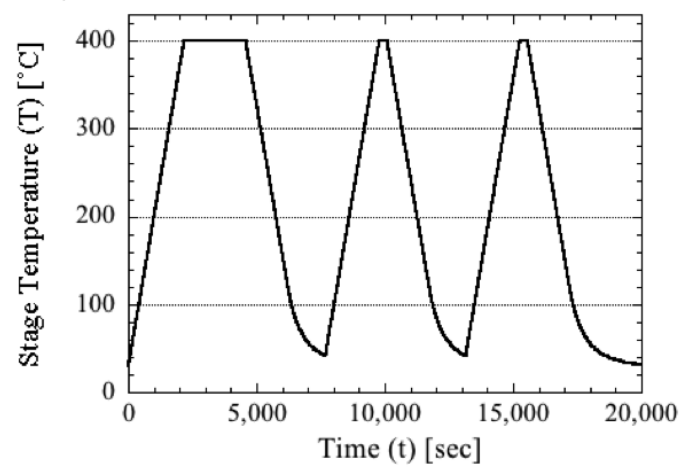

B)

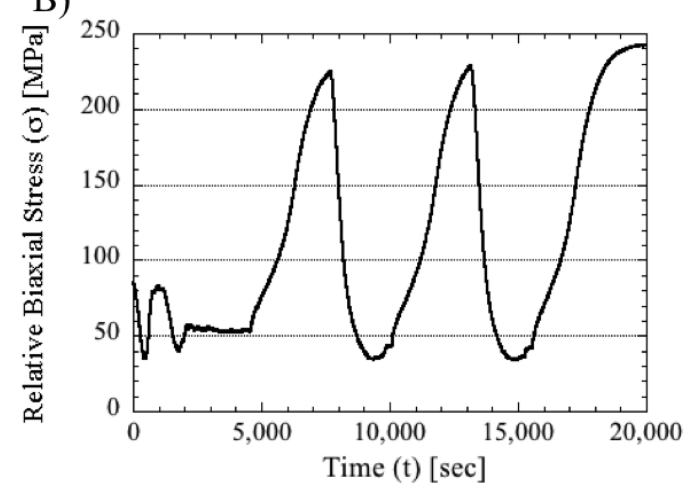

Fig. 1. A) Temperature and B) stress profiles during the progression of a representative threecycle curvature measurement test on $\mathrm{Cu} / \mathrm{Nb} \mathrm{NMM}$ systems. 
To further examine the development of residual stress in NMM systems a complimentary XRD measurement technique was used to further validate the curvature measurements. Component dependent stress in $\mathrm{NMM} \mathrm{Cu} / \mathrm{Nb}$ has been measured through the use of in-situ heated XRD. A PANalytical X'Pert Pro MRD four-circle diffractometer equipped with an Anton-Paar DHS-900 digital hot stage was used for these measurements. Stress was calculated from deviations of primary peak position measurements [Cu (111) and $\mathrm{Nb}(110)]$ from their equilibrium positions. These peak spacings were measured using a short two- $\theta$ scan while at high $\chi$ tilt $\left(85^{\circ}\right)$ to measure the in-plane direction with respect to the film, using a method similar to that previously described by Gram et al. [36]. Measurements were taken from room temperature to $400{ }^{\circ} \mathrm{C}$ in $50{ }^{\circ} \mathrm{C}$ increments during isothermal holds. Previous researchers have shown that stress measurements using both curvature and X-ray determination methods yield complimentary results for monolithic film systems [41,42].

The local lattice strain obtained from changes in primary peak spacing is material dependent, meaning that the strain values obtained are an average for all of the $\mathrm{Cu}$ layers and all of the $\mathrm{Nb}$ layers independently. Lattice strain, $\epsilon$, is given by:

$$
\epsilon(T)=\ln \left(\frac{d(T)}{d_{0}(T)}\right)
$$

where $d(T)$ is the measured lattice parameter (strained) and $d_{0}(T)$ is the stress free lattice parameter after accounting for thermal expansion determined by:

$$
d_{0}(T)=d_{0}\left(25^{\circ} C\right)+\alpha * \Delta T
$$

where $d_{0}\left(25^{\circ} \mathrm{C}\right)$ is the room temperature stress free lattice parameter taken from star quality ICCD PDF cards, $\alpha$ is the coefficient of thermal expansion (CTE) taken from the literature $[33,34]$, and $\Delta T$ is the change in temperature with respect to $25^{\circ} \mathrm{C}$. Lattice stress was calculated 
using linear elastic theory and the temperature dependent elastic constants $[43,44]$ to accommodate for the compliance of that particular crystalline direction $[\mathrm{Cu}(111)$ and $\mathrm{Nb}(110)]$ given by:

$$
E_{111}(T)=S_{11}(T)-\frac{2}{3}\left(\left(S_{11}(T)-S_{12}(T)\right)-\frac{S_{44}(T)}{2}\right)
$$

and:

$$
E_{110}(T)=S_{11}(T)-\frac{1}{2}\left(\left(S_{11}(T)-S_{12}(T)\right)-\frac{S_{44}(T)}{2}\right)
$$

where $S_{i j}(T)$ are the specific temperature-dependent compliance matrix components to determine the directional modulus as detailed by Hopcroft et al. [38]. Using the lattice strain $[\epsilon(T)]$ and the elastic modulus $\left[\left(E_{h k l}(T)\right]\right.$ the peak shifting stress was computed by:

$$
\sigma(T)=\epsilon(T) * E_{h k l}(T)
$$

assuming elastic strains, linear dependence of CTE and elastic constants with respect to temperature, and results in an average value for all of the layers of a single component $(\mathrm{Cu}$ versus $\mathrm{Nb}$ ). This heating was performed under vacuum through the use of a mechanical roughing pump, however, there were no means to measure the pressure obtained.

\section{Results and discussion}

\subsection{Initial properties of monolithic and NMM systems}

The NMM film systems contained varying amounts of initial residual stress, which are summarized in Fig. 2. Stresses were observed to range from $420 \mathrm{MPa}$ in tension to $620 \mathrm{MPa}$ in compression (Fig. 2). Compressive stresses are denoted by negative values. Samples are also included that had been deposited 14 months prior (2/2013) using the same deposition parameters. It is important to note that stresses in the samples deposited in 2/2013 were measured immediately following deposition. Since room temperature stress relief (up to 25\%) has been 
observed for $\mathrm{Mo} / \mathrm{Si}$ multilayer systems over a period of six months, these values may be overestimates [30]. For reference, the monolithic film systems and most of the NMM films were deposited just prior to the stress examination (4/2014).
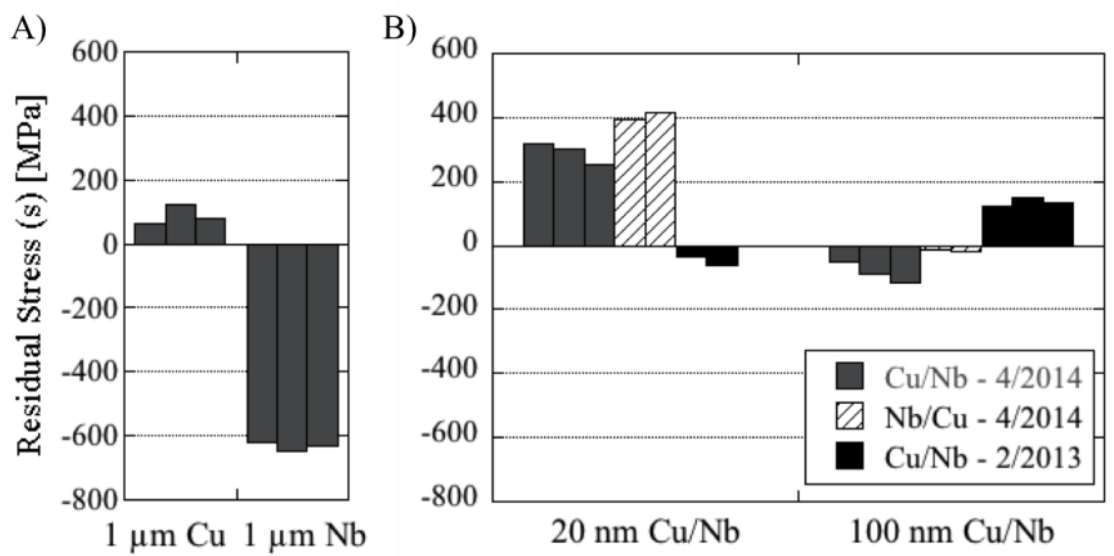

Fig. 2. Initial residual stresses of film systems for this study including (A) monolithic films and (B) NMM architectures as calculated from changes in substrate curvature. Residual stress can depend on several factors including deposition conditions, lifetime of source target, and sample history. Dates in legend indicate the date of fabrication.

Other properties of the systems produced for this study are in agreement with values expected from the literature. The as-deposited hardness values measured for monolithic films $\left(H_{\mathrm{Cu}}: 2.4 \pm 0.2 \mathrm{GPa}, H_{\mathrm{Nb}}: 5.4 \pm 0.5 \mathrm{GPa}\right)$ were consistent with both the values seen in literature for $\mathrm{Cu}(H: 2.3 \pm 0.2 \mathrm{GPa}[45])$ and $\mathrm{Nb}(H: \approx 4 \mathrm{GPa}[46])$. The monolithic film hardness measurements were also similar with those measured for the NMM systems for this study $(H: 5.2$ \pm 0.2 for $20 \mathrm{~nm} \mathrm{Cu} / \mathrm{Nb}$, and $H: 4.4 \pm 0.2 \mathrm{GPa}$ for $100 \mathrm{~nm} \mathrm{Cu} / \mathrm{Nb}$ ) and those in literature [2,9]. It was observed that for both the $\mathrm{Cu} / \mathrm{Nb}$ and $\mathrm{Nb} / \mathrm{Cu}$ geometries, hardness of the NMM systems increase as individual layer thickness is reduced [1]. Primary orientations for both $\mathrm{Cu}(111)$ and $\mathrm{Nb}$ (110) were observed by XRD. It is noted that in some instances, the diffraction peaks were significantly shifted from indexed positions, indicative of the stresses contained in the system. 
For Submission to Materials Science and Engineering A

The primary orientations observed are consistent with the Kurdjumov-Sachs orientation relationship that has been identified for $\mathrm{Cu} / \mathrm{Nb}$ NMM systems $\left[(111)_{\mathrm{Cu}(\mathrm{FCC})} \|(110)_{\mathrm{Nb}(\mathrm{BCC})}\right][47]$.

\subsection{Progression of residual stresses in monolithic films developed during thermal cycling}

As the films are heated, the components ( $\mathrm{Cu}$ film, $\mathrm{Nb}$ film, Si substrate) expand at different rates due to CTE mismatch. This varying expansion will create stress due to the confinement of the film by the substrate. CTEs for the primary components in this study are $1.65 \times 10^{-5} \mathrm{~K}^{-1}$, $7.3 \times 10^{-6} \mathrm{~K}^{-1}$, and $2.6 \times 10^{-6} \mathrm{~K}^{-1}$ for $\mathrm{Cu}, \mathrm{Nb}$, and $\mathrm{Si}$ respectively at room temperature [33,34]. It should be noted that $\mathrm{CTE}$ values are temperature dependent, but for $\mathrm{Cu}, \mathrm{Nb}$, and $\mathrm{Si}, \mathrm{Cu}$ has been shown to have the greatest value and $\mathrm{Si}$ has the least at all temperatures examined $\left(25^{\circ} \mathrm{C}\right.$ to 400 $\left.{ }^{\circ} \mathrm{C}\right)[33,34]$. By again measuring how the substrate curvature varies (as a function of temperature) through the course of a heating cycle, residual stress can be approximated for the film. The initial residual stress value determined from change in substrate curvature during deposition (Fig. 2) was used as the starting residual stress in the in-situ testing.

The initial tensile stress of the $\mathrm{Cu}$ film decreases from room temperature to $100{ }^{\circ} \mathrm{C}$, at which point the stress then increases [Fig. 3 (A) \& (B)]. Above $200{ }^{\circ} \mathrm{C}$ the stress plateaus, followed by a secondary decrease until approximately $330{ }^{\circ} \mathrm{C}$, where the stress begins to increase again. The increase in stress above $330{ }^{\circ} \mathrm{C}$ continues through the remaining heating portion, during the isothermal hold at $400{ }^{\circ} \mathrm{C}$ and throughout the entire cooling segment until room temperature. The stress behavior on initial heating [Fig. 3(B)] follows a similar stress progression with previously published results for monolithic $\mathrm{Cu}$ films [20]. Proposed mechanisms for these stress changes have been suggested to include the relief of defects due to film fabrication, the removal of Ar atoms embedded during deposition, and grain growth [20]. 

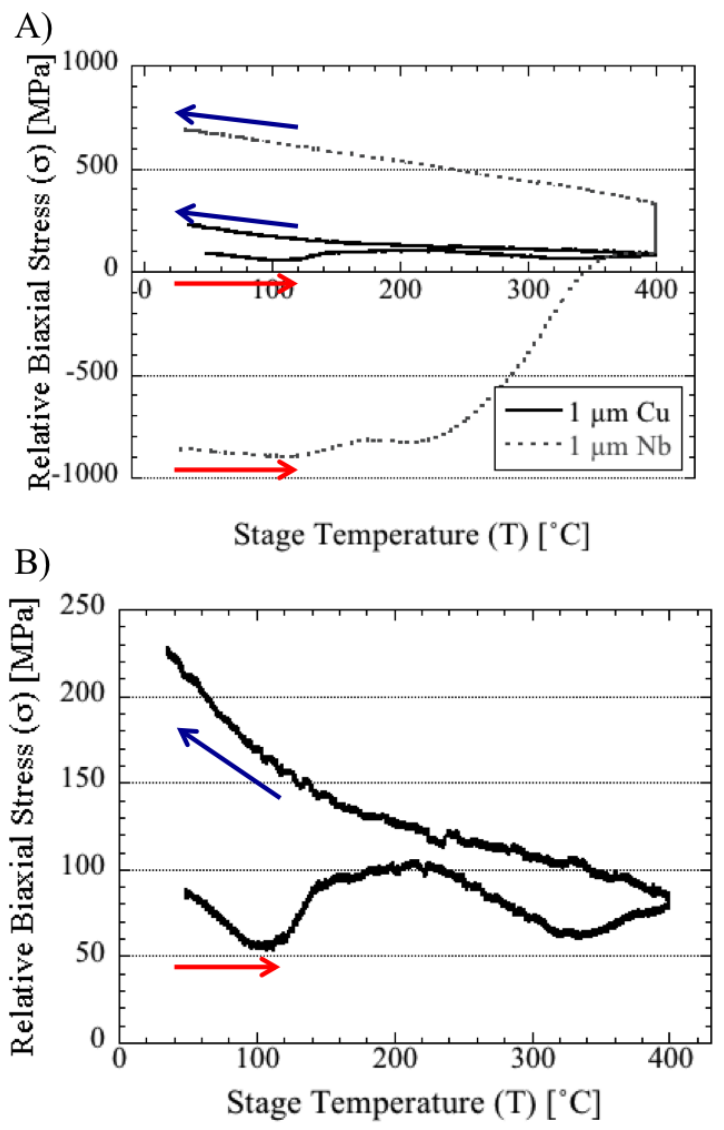

Fig. 3. Development of stress in A) one micrometer thick monolithic films a single heating cycle, with $\mathrm{B}$ ) showing a magnified scale of the monolithic $\mathrm{Cu}$ film by itself. Multiple changes in inflection are indicative of multiple mechanisms for stress evolution. Arrows indicate heating (red) and cooling (blue) segments. Initially compressive stress in the $\mathrm{Nb}$ system becomes largely tensile $(\approx 500 \mathrm{MPa})$ after the initial cycle while the stress in the $\mathrm{Cu}$ film remains modest throughout $(<200 \mathrm{MPa})$.

The stress progression in monolithic $\mathrm{Cu}$ greatly contrasts the behavior observed in $\mathrm{Nb}$ film during heating [Fig. 3(A)]. The stress evolution observed in the $\mathrm{Nb}$ film is largely consistent with behavior noted in other BCC metals published elsewhere [30]. The large initial compressive stress in the $\mathrm{Nb}$ remains mostly unchanged during heating until above $200{ }^{\circ} \mathrm{C}$, at which point it rapidly becomes tensile. During the isothermal hold, the stress increases. The stress also increases linearly during cooling. The thermoelastic slope can be extracted from these tests as the slope of the linear portions of the cooling curves [31], for $\mathrm{Nb}$ this is for temperatures 
For Submission to Materials Science and Engineering A

below $350{ }^{\circ} \mathrm{C}$ and for $\mathrm{Cu}$ this is for $\mathrm{T}<100{ }^{\circ} \mathrm{C}$. The calculated values are in accordance with accepted CTEs with respect to the Si substrate $[33,34]$. The overall difference in magnitude of stress might be expected due to the large difference in homologous temperature ranges used, a factor of the different melting temperatures of the films; $\mathrm{Cu}$, a relatively low melting metal and $\mathrm{Nb}$, which is a refractory metal $\left[1085^{\circ} \mathrm{C}(1358 \mathrm{~K})\right.$ and $2469{ }^{\circ} \mathrm{C}(2742 \mathrm{~K})$, respectively].

When the monolithic films were subjected to multiple cycle tests, similar stress results were observed for the first heating and cooling cycles [Fig. 4(A)]. After the initial heating above the deposition temperature, many of the sputter-induced defects are relieved, and all of the films progress toward tensile stresses [20]. The second and third heating cycles on $\mathrm{Cu}$ films show hysteresis [Fig. 4(B)], which is consistent with what other researchers have shown for multiple thermal cycles [20]. At lower temperatures, the stress response is primarily linear, but above 100 ${ }^{\circ} \mathrm{C}$ the heating and cooling portions deviate. The stress on heating decreases to levels achieved on the initial heating step $(<50 \mathrm{MPa})$.

Conversely, monolithic Nb films do not show significant hysteresis [Fig. 4(A)]. After the large shift toward tensile stress in the first cycle, further stress progression is largely linear. Above $350{ }^{\circ} \mathrm{C}$, the response is nonlinear. During the isothermal holds at $400{ }^{\circ} \mathrm{C}$, the stress continues to increase, indicating a possible high temperature reaction that has not yet reached completion. It is noted that the thermoelastic slopes on subsequent heating and cooling are within experimental error as compared to the initial cooling from $400{ }^{\circ} \mathrm{C}\left(m_{\mathrm{Cu}}:-0.84 \pm 0.11\right.$ $\left.\mathrm{MPa} /{ }^{\circ} \mathrm{C}, m_{\mathrm{Nb}}:-0.62 \pm 0.02 \mathrm{MPa} /{ }^{\circ} \mathrm{C}\right)$. 

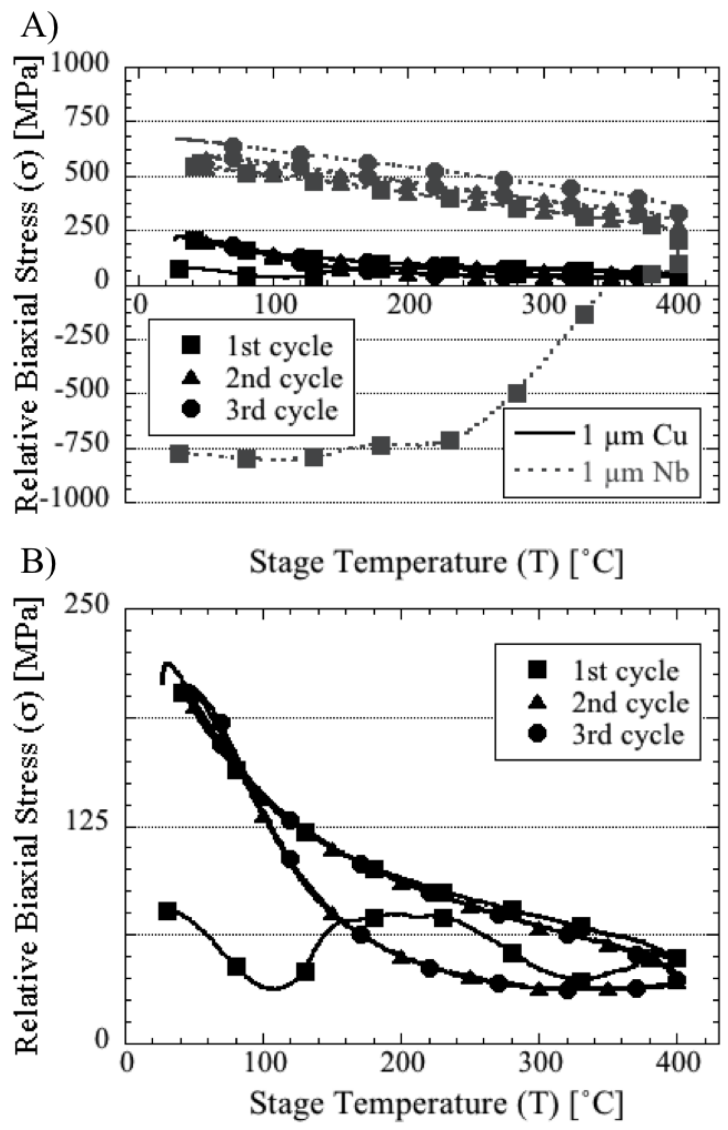

Fig. 4. Development of stress in A) one micrometer monolithic films during three heating cycles, with $\mathrm{B}$ ) showing a magnified scale of the monolithic $\mathrm{Cu}$ film by itself. The inflection changes noted on the initial heating are absent in following heating cycles. The hysteresis observed is consistent with those observed by other researchers for $\mathrm{Cu}$ films on $\mathrm{Si}$ [20]. The subsequent changes in $\mathrm{Nb}$ stress after the first cycle occur at temperatures $\approx 400{ }^{\circ} \mathrm{C}$, otherwise similar to the initial cooling step (similar slope).

\subsection{Progression of residual stresses in NMM systems developed during thermal cycling}

When NMM systems are heated, stress progressions have been observed that are comparable to the $\mathrm{Nb}$ stress response [Fig. 3(A)]. For the $20 \mathrm{~nm} \mathrm{Cu} / \mathrm{Nb}$ system, the initial tensile stress decreases upon heating from room temperature to $360{ }^{\circ} \mathrm{C}$ (Fig. 5). During the isothermal hold at $400{ }^{\circ} \mathrm{C}$, the stress continues to decrease and on cooling it linearly increases. 


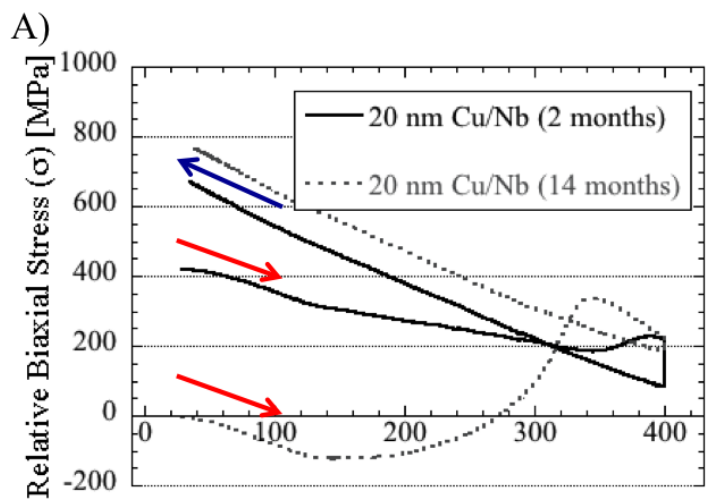

B)

Stage Temperature $(\mathrm{T})\left[{ }^{\circ} \mathrm{C}\right]$

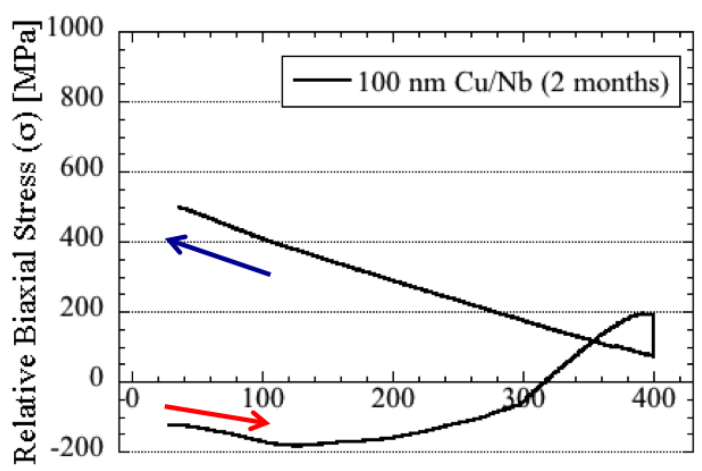

Stage Temperature $(\mathrm{T})\left[{ }^{\circ} \mathrm{C}\right]$

Fig. 5. Comparison of differing samples (architectures) on stress progression with similar temperature profiles: A) $20 \mathrm{~nm} \mathrm{Cu} / \mathrm{Nb} \mathrm{NMM}$ and B) $100 \mathrm{~nm} \mathrm{Cu} / \mathrm{Nb} \mathrm{NMM}$. In all cases the initial linear portion during heating $\left(<100{ }^{\circ} \mathrm{C}\right)$ gives way to nonlinearity, partial stress relief is observed during the isothermal hold at the maximum temperature followed by the persistence and growth of tensile stresses on cooling. Plastic behavior on heating is distinct for all samples, but linear region on cooling is consistent for specific layer thicknesses. Arrows indicate heating (red) and cooling (blue) segments.

A $20 \mathrm{~nm} \mathrm{Cu} / \mathrm{Nb} \mathrm{NMM}$ sample was deposited and then stored for 14 months. It was then tested in an identical fashion to the other NMM films (Fig. 5). The stresses developed were similar to the progression observed for monolithic $\mathrm{Nb}$ films [Fig. 3(A)]. Upon heating, the stress becomes initially more compressive followed by a large increase above $200{ }^{\circ} \mathrm{C}$. Around $350{ }^{\circ} \mathrm{C}$, the tensile stress decreases, this decrease in stress continues through the isothermal hold at 400 ${ }^{\circ} \mathrm{C}$. On cooling, the tensile stress increases linearly. 
For Submission to Materials Science and Engineering A

This behavior is also seen for the $100 \mathrm{~nm} \mathrm{Cu} / \mathrm{Nb}$ system (Fig. 5). The most notable differences between the two tests $(100 \mathrm{~nm} \mathrm{Cu} / \mathrm{Nb} \mathrm{NMM}$ and $20 \mathrm{~nm} \mathrm{Cu} / \mathrm{Nb} \mathrm{NMM}$ that was deposited 14 month prior) are that the onset of stress relief at high temperatures does not begin until $400{ }^{\circ} \mathrm{C}$ for the $100 \mathrm{~nm}$ system and the $20 \mathrm{~nm}$ system has a larger overall net change in stress (550 MPa for $20 \mathrm{~nm}$ vs. $450 \mathrm{MPa}$ for $100 \mathrm{~nm}$ ). Both of these systems began with initially compressive stresses whereas the newly deposited $20 \mathrm{~nm}$ system had a tensile stress of $300 \mathrm{MPa}$ at the beginning of the test.

It can be seen that despite the large preliminary gap from deposition stresses between the older and newer $20 \mathrm{~nm}$ system, upon initial heating $\left(<150{ }^{\circ} \mathrm{C}\right)$ they both show a similar rate of change $\left(m:-1.23 \pm 0.09 \mathrm{MPa} /{ }^{\circ} \mathrm{C}\right.$ for the $20 \mathrm{~nm}$ sample after two months vs. $-1.28 \mathrm{MPa} /{ }^{\circ} \mathrm{C}$ for the $20 \mathrm{~nm}$ sample after 14 months). Additionally, during cooling both $20 \mathrm{~nm}$ geometries show similar responses, the two curves are parallel for the entirety of the cooling segment. Even though their initial stress states were more than $300 \mathrm{MPa}$ apart, their final stresses after heating to $400{ }^{\circ} \mathrm{C}$ and cooling to room temperature are within $100 \mathrm{MPa}$. This is not observed for the 100 nm system; although the $100 \mathrm{~nm}$ system displays a similar hysteresis to the older $20 \mathrm{~nm}$ sample, the slopes on initial heating and cooling are dissimilar. This highlights the importance of the NMM architecture over the initial stress conditions imposed by deposition. Additionally, some researchers have mitigated the first cycle effect by short annealing steps prior to their thermal cycling stress measurements [20].

Comparing the stresses developed in the NMM geometries (Fig. 5) with those observed in monolithic $\mathrm{Nb}$ (Fig. 3), one key difference is noted. A new peak is observed at approximately $350{ }^{\circ} \mathrm{C}$ to $400{ }^{\circ} \mathrm{C}$ in $\mathrm{NMM}$ systems (Fig. 5). It is hypothesized that the overall maximum stress achievable in the NMM systems at high temperatures is limited by the high-temperature yield 
For Submission to Materials Science and Engineering A

strength of the $\mathrm{Cu}$ layers. Other researchers have measured the hot-hardness of $\mathrm{Cu}$ to be below 1 $\mathrm{GPa}$ at $400{ }^{\circ} \mathrm{C}$ [48]. The decreased yield strength of $\mathrm{Cu}$ layers combined with the high stress of the $\mathrm{Nb}$ layers would indicate that yielding may occur due to the stresses measured in NMMs at high temperature. However, this would be limited to the $\mathrm{Cu}$ components of the NMMs as $\mathrm{Nb}$ has a much greater melting temperature $\left[1085{ }^{\circ} \mathrm{C}(1358 \mathrm{~K})\right.$ and $2469{ }^{\circ} \mathrm{C}(2742 \mathrm{~K})$ for $\mathrm{Cu}$ and $\mathrm{Nb}$, respectively].

The CTE mismatch that is often considered of importance is between that of the substrate and the film in contact with the substrate. NMM geometries with opposing geometries (both $\mathrm{Cu}$ and $\mathrm{Nb}$ as base layers) were utilized in order to examine the importance of layer order on stress development. Aside from the layer order, the sample architectures were equivalent.

The NMM systems with $\mathrm{Cu}$ as the base layer were presented in Fig. 5 and are included here for comparison. For both layer thicknesses examined (20 nm [Fig. 6(A)] and $100 \mathrm{~nm}$ [Fig. 6(B)]) the $\mathrm{Nb} / \mathrm{Cu}$ stress evolution is similar to what was observed for the $\mathrm{Cu} / \mathrm{Nb}$ systems (Table 2). Two key deviations were observed: the onset of the peak on heating occurs at lower temperatures, and there is a larger variation in stress. For the $\mathrm{Cu} / \mathrm{Nb}$ systems the stress reaches a peak at approximately $400{ }^{\circ} \mathrm{C}$. However for the $\mathrm{Nb} / \mathrm{Cu}$ systems, this peak is observed between $300{ }^{\circ} \mathrm{C}$ and $350{ }^{\circ} \mathrm{C}$ [Fig. 6 (A) \& (B)]. Most notable is that the slopes on cooling are equivalent for the different layer orders.

\section{Table 2}

Calculated thermoelastic slope values for NMM systems taken from linear regressions during cooling.

\begin{tabular}{ccc}
\hline Layer & \multicolumn{2}{c}{ Layer Geometry } \\
\cline { 2 - 3 } Architecture & $\mathrm{Cu} / \mathrm{Nb}$ NMM Systems & Nb/Cu NMM Systems \\
\hline $20 \mathrm{~nm}$ & $-1.23 \pm 0.09 \mathrm{MPa} /{ }^{\circ} \mathrm{C}$ & $-1.11 \pm 0.09 \mathrm{MPa} /{ }^{\circ} \mathrm{C}$ \\
$100 \mathrm{~nm}$ & $-0.89 \pm 0.03 \mathrm{MPa} /{ }^{\circ} \mathrm{C}$ & $-0.82 \pm 0.07 \mathrm{MPa} /{ }^{\circ} \mathrm{C}$ \\
\hline
\end{tabular}



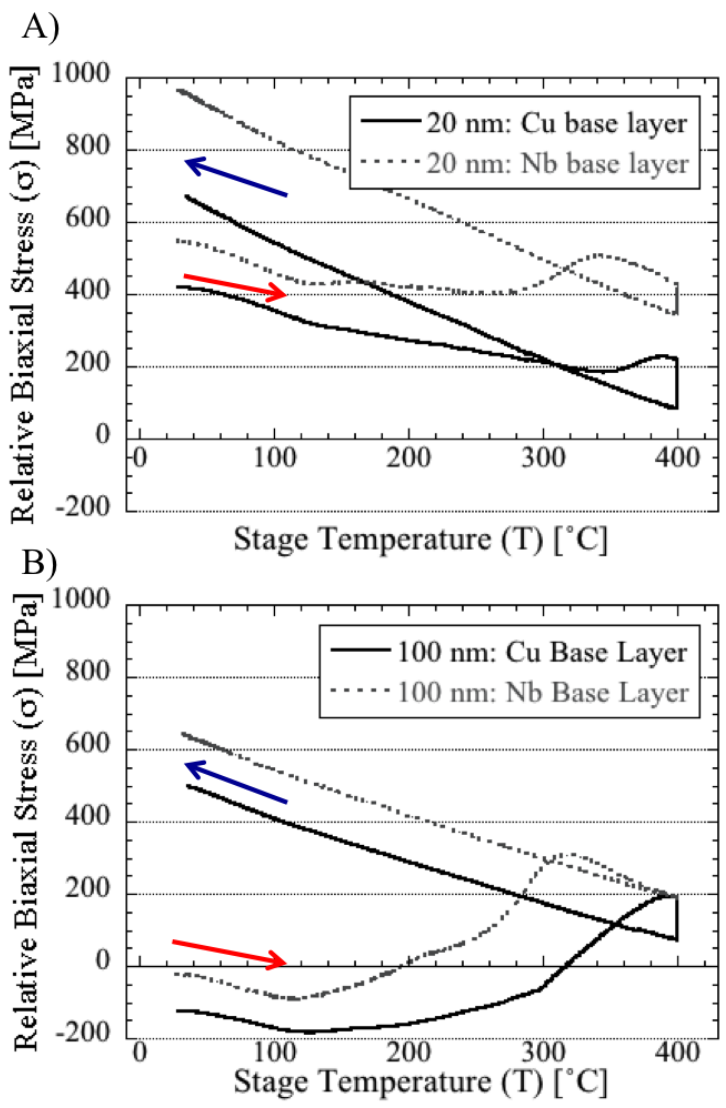

Fig. 6. Comparisons of (A) $20 \mathrm{~nm}$ and (B) $100 \mathrm{~nm} \mathrm{Nb} / \mathrm{Cu}$ (Nb film as a base layer) with similar $\mathrm{Cu} / \mathrm{Nb}$ systems showing the effect of layer order on development of stress during heating to 400 ${ }^{\circ} \mathrm{C}$. A larger stress is developed for the system with $\mathrm{Nb}$ as a base layer with more pronounced features, however the slopes of the linear regions during cooling are consistent for specific layer thicknesses.

A t-test comparing the slope values for the 20 and $100 \mathrm{~nm}$ including both $\mathrm{Cu} / \mathrm{Nb}$ and $\mathrm{Nb} / \mathrm{Cu}$ geometries indicates that there is a significant difference with respect to layer thickness ( $\mathrm{p}$-value: $>0.001$ ). By compiling the thermoelastic slope values (Table 2) for all of the linear portions of the cooling curves for the tests performed into a graph (shown in Fig. 7), it is seen that as layer thickness is reduced, the thermoelastic slope becomes more negative. This means that in NMM systems, thinner layers will develop greater tensile stresses during cooling in the thickness range that has been examined. This relationship also includes the results from stress measurements of 2 
$\mathrm{nm} \mathrm{Cu} / \mathrm{Nb} \mathrm{NMM}$ system with a total thickness of $10 \mu \mathrm{m}$. Poor adhesion resulted in these tests failing and delaminating before completion of the thermal cycle. However, the thermoelastic slope could still be determined from the limited test of the $2 \mathrm{~nm} \mathrm{Cu} / \mathrm{Nb} \mathrm{NMM}$ system.

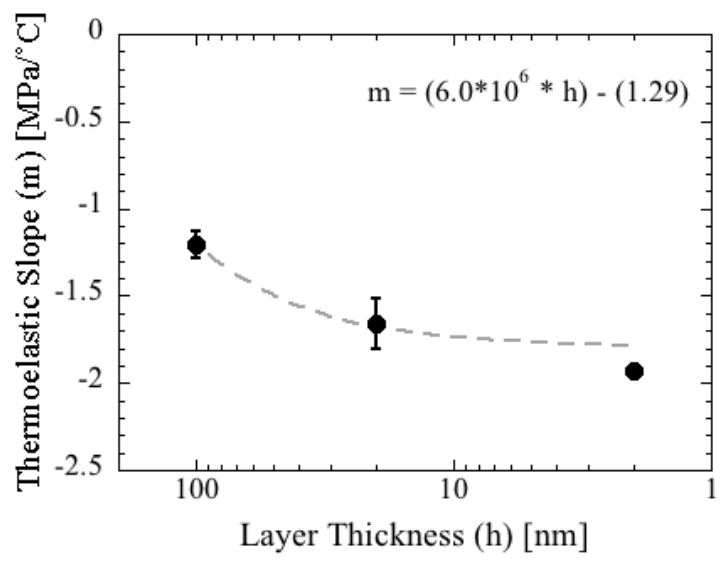

Fig. 7. Thermoelastic slope of varying NMM architectures. Systems with thinner layers have more negative values indicating that more thermal stresses are developed. This is suggested to be due to the increased impact of interfacial stresses, which are omitted in established models.

Traditional descriptions of estimations of the thermoelastic slope do not include terms that would account for changes in layer thickness [31]. It might be suggested that the layer thickness dependent behavior becomes appreciable when the interfacial density becomes significant enough $(\mathrm{h}<\approx 100 \mathrm{~nm})$ to allow for interfacial stress dependent phenomenon to occur. As the layer thickness is further reduced, the thermoelastic slope becomes more negative until a minimum is reached, where the layered structure becomes so thin that layer continuity is an issue. An initial linear regression shows that the thermoelastic slope, $m$, follows:

$$
m=6.0 \times 10^{6} * h-1.29
$$

where, $h$ is the individual layer thickness following linear fitting. The determined values of thermoelastic slope $\left(-1.21 \mathrm{MPa} /{ }^{\circ} \mathrm{C}\right.$ to $\left.-1.93 \mathrm{MPa} /{ }^{\circ} \mathrm{C}\right)$ are near the predicted value for $\mathrm{Cu} / \mathrm{Nb}$ of $-1.8 \mathrm{MPa} /{ }^{\circ} \mathrm{C}$. A linear fit was chosen due to the limited data available, which explained $82 \%$ of 
the variance. If the previously established approximation of thermoelastic slope (Eq. 1) [31] is combined with the relationship determined from the stress response of $\mathrm{Cu} / \mathrm{Nb} \mathrm{NMM}$ systems (Eq. 8) it is seen that the thermoelastic slope of NMM systems $(h<\approx 100 \mathrm{~nm})$ follows:

$$
m=k * h+\left(\frac{E_{f}}{v_{f}}\right) \Delta \alpha
$$

where $k$ is a system dependent constant found from the regression $\left(k_{C u / N b}: 6.0 \times 10^{6} \mathrm{MPa} / \mathrm{m}^{\circ} \mathrm{C}\right), h$ is the individual layer thickness (in meters), $E_{f}$ is the film elastic modulus, $v_{f}$ is the Poisson's ratio of the film, and $\Delta \alpha$ is the $\mathrm{CTE}$ mismatch in between the composite film system and substrate. However, it is suggested that this approach be applied to additional layer thicknesses of different NMM systems to better understand the relationship between layer thickness and thermoelastic slope. This dependence was not identified by Windt [30] or Gram et al. [36], probably due to the narrow range of layer thicknesses examined in those previous studies. Presently, almost two orders of magnitude in layer thickness were examined in comparison to Windt's examination of 1 to $5 \mathrm{~nm}$ individual layered systems [30] or $11 \mathrm{~nm}$ and $21 \mathrm{~nm} \mathrm{Cu} / \mathrm{Ni}$ by Gram et al. [36]. It is noted that there are other considerable structural differences between the $\mathrm{Cu} / \mathrm{Nb} \mathrm{NMM}$ systems examined in the present study and the $\mathrm{Cu} / \mathrm{Ni}$ examined by Gram et al. [36] and $\mathrm{Mo} / \mathrm{Si}$ examined by Windt [30] including interfacial coherency (incoherent for $\mathrm{Cu} / \mathrm{Nb}$ and nearly coherent for $\mathrm{Cu} / \mathrm{Ni}$ ) and elastic modulus mismatch. The impact of elastic modulus can be seen in the initial approximation of thermoelastic slope (Eq. 1) where greater values result in larger stresses [31]. Further, the interfacial coherency is likely to impact the development of the interfacial stresses that have been attributed to the change in layer thickness, but the full impact is not yet known. 


\subsection{Influence of multiple cycles on thermal stresses in NMM systems}

Testing consisting of three successive thermal cycles were used to examine the stress response of NMMs after initial deposition defects occurred [20]. It was observed that for all samples, the initial heating segment closely matched the single cycle tests presented in the previous section (3.3). On subsequent cycles, the $20 \mathrm{~nm} \mathrm{Cu} / \mathrm{Nb} \mathrm{NMM}$ system follows a cyclical progression, similar to what was measured for the initial cooling segment (Fig. 8). Above 200 ${ }^{\circ} \mathrm{C}$, the stress progression is linear. However, at lower temperatures non-linearity is observed, as determined by deviations from a linear fit.

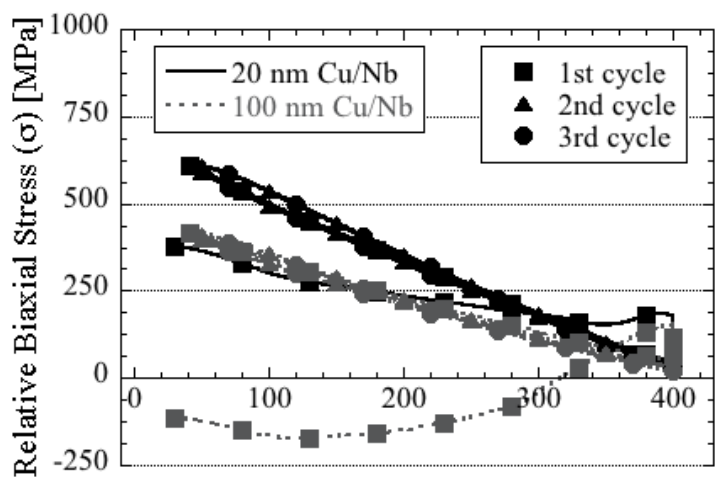

Stage Temperature $(\mathrm{T})\left[{ }^{\circ} \mathrm{C}\right]$

Fig. 8. Development of stress in 20 and $100 \mathrm{~nm} \mathrm{Cu} / \mathrm{Nb}$ NMM films upon three heating cycles to $400{ }^{\circ} \mathrm{C}$ at $10{ }^{\circ} \mathrm{C} / \mathrm{min}$. The inflection changes noted on the initial heating are absent in subsequent heating cycles. The hysteresis observed is largely consistent with those noted in the monolithic systems. At lower temperatures $\left(<200{ }^{\circ} \mathrm{C}\right)$ non-linear behavior is observed for the $20 \mathrm{~nm}$ system.

Linearity on subsequent cycles is also noted for the $100 \mathrm{~nm} \mathrm{Cu} / \mathrm{Nb}$ system (Fig. 8) and the other geometries examined $(20 \mathrm{~nm} \mathrm{Nb} / \mathrm{Cu}$ and $100 \mathrm{~nm} \mathrm{Nb} / \mathrm{Cu})$. When compared with the results from monolithic systems (Section 3.2), it is observed that, much like the initial cycle, the hysteresis is comparable with monolithic $\mathrm{Nb}$ films. These hystereses, although small, can be repeatedly observed as these stress profiles were measured two to three times for each condition. The deviations between stress on heating and cooling for $\mathrm{Cu}$ films above $100{ }^{\circ} \mathrm{C}$ (Fig. 4) are 
For Submission to Materials Science and Engineering A

absent in NMM systems. However, the continued development of larger tensile stresses in $\mathrm{Nb}$ films (Fig. 4) during the second and third isothermal hold at $400{ }^{\circ} \mathrm{C}$ are also notably absent from the NMM systems.

These results point to an important aspect, stress related system evolution is going to likely occur during the first thermal cycle. On subsequent cycles, the stress is traveling close to the path the sample followed on the initial cooling segment. If the stresses observed during the first cycle are insufficient to initiate degradation it is not likely that it will occur on following cycles.

\subsection{Comparison of curvature stress with XRD stress}

From in-situ heated XRD examination, it is observed that an older $20 \mathrm{~nm} \mathrm{Cu} / \mathrm{Nb} \mathrm{NMM}$ system exhibits very distinct stress behavior for the $\mathrm{Cu}$ and $\mathrm{Nb}$ components (Fig. 9). Upon heating, the stresses measured in the $\mathrm{Nb}$ layers remain constant until above $175{ }^{\circ} \mathrm{C}$, after which point they greatly increase. The stresses in the $\mathrm{Nb}$ layers then persist throughout the duration of the test. Contrastingly, the stresses measured in the $\mathrm{Cu}$ layers do not show this drastic change; on heating there are initial drops in stresses up until $175^{\circ} \mathrm{C}$ at which point the stresses increase again to a moderate value. On cooling, the stresses in the $\mathrm{Cu}$ layers increase relatively linearly. These stresses are consistent with a tensile stress in the film and a compressive stress in the substrate as should be expected from the CTE mismatch, however the absolute stress values are dependent on an accurate stress-free initial lattice parameter [36]. 


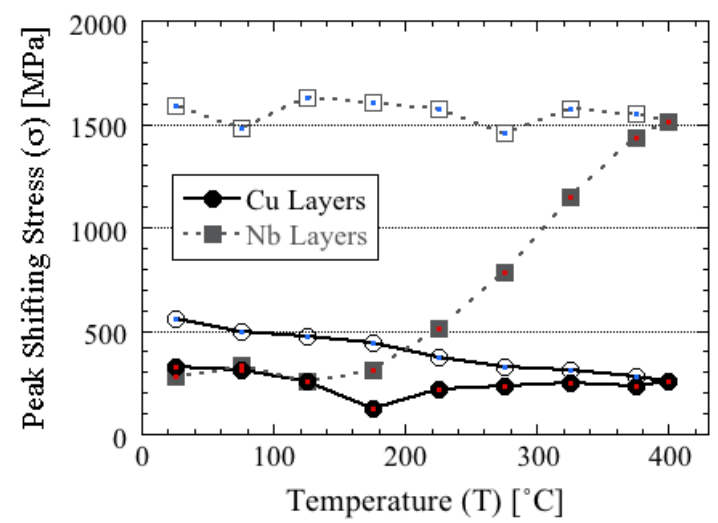

Fig. 9. Development of stresses in $20 \mathrm{~nm} \mathrm{Cu} / \mathrm{Nb} \mathrm{NMM}$ system as calculated from measured lattice strain by in-plane XRD showing similar progression to what was observed for monolithic films by changes in curvature. In this case, stress is approximated using changes in peak position of primary $\mathrm{Cu}$ and $\mathrm{Nb}$ orientations as a measure of lattice strain. Closed red markers indicate heating, open blue markers indicate cooling, markers indicate where measurements were taken and the connecting lines are to guide the eye.

The stress behavior in the NMM system appears to show the same trends as were measured in the monolithic films by substrate curvature (Fig. 3). This is an important distinction: the stress measured in the individual layers of a composite system is consistent with the stress behavior of a similar single component under similar conditions. These results show similar trends to those seen in the $\mathrm{Cu} / \mathrm{Ni} \mathrm{NMM}$ systems examined by Gram et al. [36]. However, it is noted that the $\mathrm{Nb}$ response seen in the present study (Fig. 9) is dissimilar from the Ni stress response seen by Gram et al. [36], this is contrasted with the response expected of monolithic BCC metals seen in the literature [30]. Notably absent from the XRD measurements (Fig. 9) is the peak observed for the NMM systems $\left(350{ }^{\circ} \mathrm{C}\right.$ to $400{ }^{\circ} \mathrm{C}$, Fig. 6$)$.

Comparing the stress measurements from substrate curvature measurements and from XRD give two different responses: the composite stress and a phase specific approximation of stress. Bearing in mind the implications of residual stress, both values can be important design considerations depending on the application. If the NMM system is treated as a single 
For Submission to Materials Science and Engineering A

component (e.g. overall coating behavior) the curvature measurement is of greater interest. However, in understanding the behavior in a single layer (e.g. dislocation motion), then measuring the stress on a local level with XRD would be more pertinent.

\subsection{Post-heating confirmation of structure and properties}

Substantial grain growth was observed for monolithic $\mathrm{Cu}$ due to heating, as determined by AFM. The initial $\mathrm{Cu}$ grain size was $83 \mathrm{~nm}$, which grew to $140 \mathrm{~nm}$ after heating. These measurements were also corroborated with EBSD measurements (grain size: $160 \pm 30 \mathrm{~nm}$ ). However, grain growth was not observed for the monolithic $\mathrm{Nb}$ film. Both before and after heating, the grain sizes were approximately $60 \mathrm{~nm}$. This is to be expected considering the melting temperatures of $\mathrm{Cu}$ and $\mathrm{Nb}, 1085{ }^{\circ} \mathrm{C}(1358 \mathrm{~K})$ and $2469{ }^{\circ} \mathrm{C}(2742 \mathrm{~K})$ respectively. The temperature associated with grain growth in bulk metals is often assumed to be approximately half of the melting temperature $\left[406{ }^{\circ} \mathrm{C}(679 \mathrm{~K})\right.$ and $1098{ }^{\circ} \mathrm{C}(1371 \mathrm{~K})$ for $\mathrm{Cu}$ and $\mathrm{Nb}$, respectively].

Appreciable grain growth in the $\mathrm{Cu}$ layer for the NMM systems examined was also observed. Initial grain sizes of the uppermost layers in both 20 and $100 \mathrm{~nm}$ architectures were approximately $42 \mathrm{~nm}$. After heating the grains grew, but still remained sub-150 nm (100 $\pm 6 \mathrm{~nm}$ and $127 \pm 9 \mathrm{~nm}$ for $20 \mathrm{~nm}$ and $100 \mathrm{~nm} \mathrm{Nb} / \mathrm{Cu}$ architectures, respectively). Previous reports indicate that the NMM structure allows for minimal grain growth during heating resulting in grains remaining largely nanocrystalline [9]. These measurements were taken from AFM scans of the uppermost layer of the NMM systems, which in the case of $\mathrm{Nb} / \mathrm{Cu}$ is $\mathrm{Cu}$. AFM measurements of the film surface could be impacted by the formation of a surface oxide, but it is estimated that substantial oxidation was not observed, as the surfaces remained highly reflective, 
For Submission to Materials Science and Engineering A

copper colored, and XRD did not reveal the formation of additional peaks pertaining to an oxide phase (Fig. 10).

XRD of the Nb/Cu NMM systems shows minimal changes to the observed phases (Fig. 10). The primary peaks observed following deposition persist with similar relative intensities to the previous measurements. Negligible changes in XRD peaks should be expected as $\mathrm{Cu}$ and $\mathrm{Nb}$ are completely insoluble in one another [28]; no intermetallic compounds should be formed. The XRD results serve to indicate that there was minimal impact of the thermal cycling seen herein on the observable structure of the NMM systems. For the conditions examined in this study, softening was not observed, as the authors have previously seen [9]. Rather, an increase in hardness for all systems was observed (e.g. $\mathrm{H}_{\text {ini }}$ : $4.7 \pm 0.2 \mathrm{GPa}$ and $\mathrm{H}_{\text {final }}$ : $5.8 \pm 0.2 \mathrm{GPa}$ for 20 $\mathrm{nm} \mathrm{Nb} / \mathrm{Cu}$ ), which is consistent with other researchers' observations [23,24,49,50].

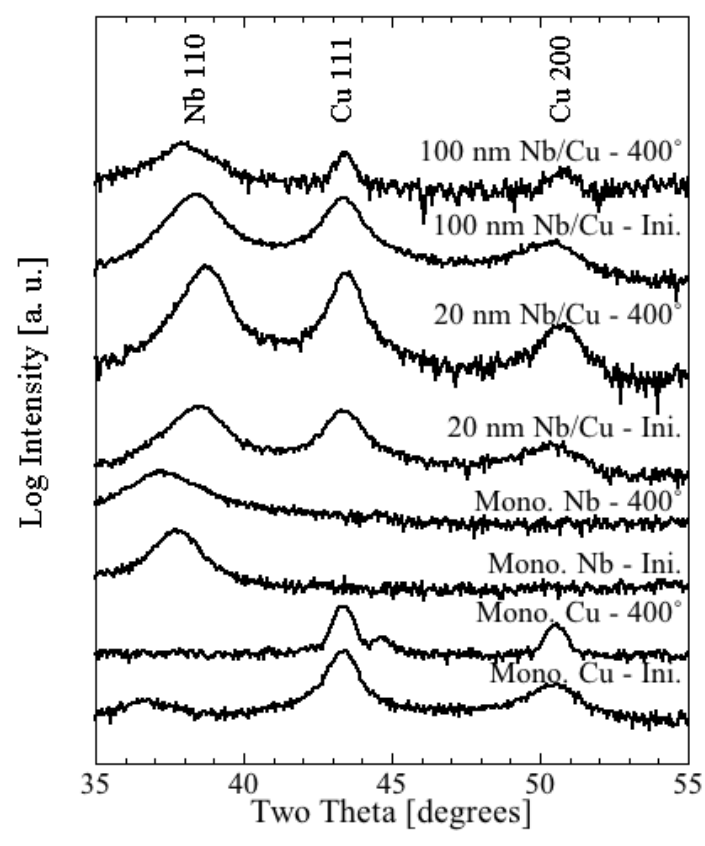

Fig. 10. XRD patterns of film systems for this study before and after heating to $400{ }^{\circ} \mathrm{C}$ including monolithic films and NMM architectures. Diffraction peaks indicate primary orientations of $\mathrm{Cu}$ and $\mathrm{Nb}$ components. The $\mathrm{Nb}$ peak shifts significantly indicative of large tensile stresses in the film. Minimal differences are observed between initial and final states indicating negligible structural changes in the films due to heating. 


\section{Conclusions}

To clarify the development of residual stresses in $\mathrm{NMM} \mathrm{Cu/Nb}$ during thermal cycling, changes in substrate curvature were measured using an in-situ measurement system. Through the examination of residual stresses developed during thermal cycling of $\mathrm{Cu} / \mathrm{Nb} \mathrm{NMM}$ systems, it has been determined that the $\mathrm{Nb}$ component largely controls the stress of the system. Using complimentary stress measurement techniques (substrate curvature and XRD) the differences between composite and phase specific stresses have been identified. The stresses developed in $\mathrm{Cu}$ and $\mathrm{Nb}$ layers as measured by XRD follow similar trends to those in monolithic systems measured with wafer curvature. This is contrasted to the hysteresis observed as measured by substrate curvature, which can be considered a composite stress for the multicomponent system. By identifying deviations between the composite stress (substrate curvature) and phase stresses (XRD), it is hypothesized that the decreasing yield strength at elevated temperatures of $\mathrm{Cu}$ and high stress of $\mathrm{Nb}$ layers may have acted together to limit the stress development above $300{ }^{\circ} \mathrm{C}$.

The layer thickness affects the stress progression during thermal cycling. It was observed that there is a distinct change in the thermoelastic slope of the stress developed on cooling for the different layer thicknesses, highlighting the importance of interfacial stresses in these nanostructured materials. Stress in these NMM systems should not be treated as a rule of mixtures considering only the volume fraction of the constituents. The interfacial density is also an important consideration. Initial stress will dictate the stress progression during the preliminary heating, but after that point the stress response on cooling and subsequent cycles is equivalent. 
For Submission to Materials Science and Engineering A

In this study, softening of the NMM structures was not observed as has been previously identified for $\mathrm{Cu} / \mathrm{Nb} \mathrm{NMM}$ systems still bound to their substrate [9]. However, the uniformity of hardness after thermal cycling is consistent with other researcher's observations on other NMM systems $[23,49,50]$. It is still supposed that there is a link between the residual stress of these systems and their thermal stability [11].

\section{Acknowledgments}

In-situ heated XRD measurements were performed at the Center for Nanophase Materials Sciences, which is a DOE Office of Science User Facility. The authors wish to acknowledge the assistance of Dr. W. Heinz (K-AI GmbH), Dr. J. E. Harriss (Clemson University), Dr. L. V. Saraf (Clemson University), Mr. B. M. Schultz (Clemson University), Dipl.-Ing. S. P. Bigl (Montanuniversitaet Leoben), and Dr. T. Schöberl (Erich Schmid Institute) for their helpful discussions and guidance. This work was partially supported by funding from the Austrian Marshall Plan Foundation. 
For Submission to Materials Science and Engineering A

\section{References}

[1] A. Misra, in:, R.H.J. Hannick Hill, A. J. (Ed.), Nanostructure Control Mater., Woodhead Publishing, Cambridge, England, 2006, pp. 146-176.

[2] A. Misra, J.P. Hirth, R.G. Hoagland, Acta Mater. 53 (2005) 4817.

[3] N.A. Mara, I.J. Beyerlein, J. Mater. Sci. 49 (2014) 6497.

[4] I.J. Beyerlein, A. Caro, M.J. Demkowicz, N.A. Mara, A. Misra, B.P.P. Uberuaga, Mater. Today 16 (2013) 443.

[5] W. Han, M.J. Demkowicz, N.A. Mara, E. Fu, S. Sinha, A.D. Rollett, Y. Wang, J.S. Carpenter, I.J. Beyerlein, A. Misra, Adv. Mater. (2013) 6975.

[6] A. Misra, M.J. Demkowicz, X. Zhang, R.G. Hoagland, JOM 59 (2007) 62.

[7] S. Wen, R. Zong, F. Zeng, Y. Gao, F. Pan, Wear 265 (2008) 1808.

[8] A. Haseeb, J. Celis, J. Roos, Thin Solid Films 444 (2003) 199.

[9] D.R. Economy, B.M. Schultz, M.S. Kennedy, J. Mater. Sci. 47 (2012) 6986.

[10] D. Josell, F. Spaepen, MRS Bull. 24 (1999) 39.

[11] D. Josell, W. Carter, J. Bonevich, Nanostructured Mater. 12 (1999) 387.

[12] A. Lewis, D. Josell, T. Weihs, Scr. Mater. 48 (2003) 1079.

[13] R.W. Balluffi, S. Allen, W.C. Carter, Kinetics of Materials, John Wiley \& Sons, 2005.

[14] J.P. Hirth, Scr. Mater. 50 (2004) 793.

[15] A.C. Fischer-Cripps, Nanoindentation, Springer, New York, 2004. 


\section{For Submission to Materials Science and Engineering A}

[16] L. Ling, S. Long, Z. Ma, X. Liang, J. Mater. Sci. Technol. 26 (2010) 1001.

[17] J. Weertman, J. Weertman, Elementary Dislocation Theory, Macmillan, 1966.

[18] C.C. Montarou, T.K. Gaylord, A.I. Dachevski, Opt. Commun. 265 (2006) 29.

[19] M. Ohring, Materials Science of Thin Films, 2nd ed., Academic Press, San Diego, CA, 2002.

[20] J.J. Toomey, S. Hymes, S.P. Murarka, Appl. Phys. Lett. 66 (1995) 2074.

[21] C.C. Chama, J.J. Vlassak, W.O. Soboyejo, Mater. Sci. Eng. A 532 (2012) 414.

[22] A.A. Taylor, S.H. Oh, G. Dehm, J. Mater. Sci. 45 (2010) 3874.

[23] S. Zheng, I.J. Beyerlein, J.S. Carpenter, K. Kang, J. Wang, W. Han, N.A. Mara, Nat. Commun. 4 (2013) 1696.

[24] A. Misra, R.G. Hoagland, J. Mater. Res. 20 (2005) 2046.

[25] W.Z. Han, N.A. Mara, Y.Q. Wang, A. Misra, M.J. Demkowicz, J. Nucl. Mater. 452 (2014) 57.

[26] K. Hattar, A. Misra, M. Dosanjh, J. Eng. Mater. Technol. 134 (2012) 21014.

[27] N. Li, J. Wang, A. Misra, J.Y. Huang, Microsc. Microanal. 18 (2012) 1155.

[28] L. Kaufman, H. Nesor, Calphad 2 (1978) 81.

[29] C.-H. Hsueh, J. Appl. Phys. 91 (2002) 9652.

[30] D.L. Windt, J. Vac. Sci. Technol. A Vacuum, Surfaces, Film. 18 (2000) 980.

[31] R.-M. Keller, S.P. Baker, E. Arzt, Acta Mater. 47 (1999) 415.

[32] R. Vinci, E. Zielinski, J. Bravman, Thin Solid Films 262 (1995) 142. 


\section{For Submission to Materials Science and Engineering A}

[33] Y.S. Touloukian, R.K. Kirby, R.E. Taylor, P.D. Desai, THERMOPHYSICAL, E.P.I.A.C.L. IN., Thermophysical Properties of Matter - the TPRC Data Series. Volume 12. Thermal Expansion Metallic Elements and Alloys, Defense Technical Information Center, 1975.

[34] Y.S. Touloukian, R.K. Kirby, E.R. Taylor, T.Y.R. Lee, THERMOPHYSICAL, E.P.I.A.C.L. IN., Thermophysical Properties of Matter - the TPRC Data Series. Volume 13. Thermal Expansion - Nonmetallic Solids, Defense Technical Information Center, 1977.

[35] J.-M. Zhang, Y. Zhang, K.-W. Xu, V. Ji, J. Phys. Chem. Solids 68 (2007) 503.

[36] M.D. Gram, J.S. Carpenter, E.A. Payzant, A. Misra, P.M. Anderson, Mater. Res. Lett. 1 (2013) 233.

[37] V. Ramaswamy, W.D. Nix, B.M. Clemens, Scr. Mater. 50 (2004) 711.

[38] M.A. Hopcroft, W.D. Nix, T.W. Kenny, Microelectromechanical Syst. J. 19 (2010) 229.

[39] G. Stoney, Proc. R. Soc. London. Ser. A 82 (1909) 172.

[40] W.C. Oliver, G.M. Pharr, J. Mater. Res. 7 (1992) 1564.

[41] E. Eiper, J. Keckes, K.J. Martinschitz, I. Zizak, M. Cabié, G. Dehm, Acta Mater. 55 (2007) 1941.

[42] O. Kraft, M. Hommel, E. Arzt, Mater. Sci. Eng. A 288 (2000) 209.

[43] Y. Talmor, E. Walker, S. Steinemann, Solid State Commun. 23 (1977) 649.

[44] Y.A. Chang, J. Appl. Phys. 37 (1966) 3567.

[45] D. Beegan, S. Chowdhury, M.T. Laugier, Surf. Coatings Technol. 201 (2007) 5804.

[46] L. Kommel, E. Kimmari, M. Saarna, M. Viljus, J. Mater. Sci. 48 (2013) 4723.

[47] K. Yu-Zhang, J.D. Embury, K. Han, A. Misra, Philos. Mag. 88 (2008) 2559. 


\section{For Submission to Materials Science and Engineering A}

[48] C.A. Schuh, C.E. Packard, A.C. Lund, J. Mater. Res. 21 (2006) 725.

[49] R.L. Schoeppner, N. Abdolrahim, I. Salehinia, H.M. Zbib, D.F. Bahr, Thin Solid Films 571 (2014) 247.

[50] N.A. Mara, A. Misra, R.G. Hoagland, A. V Sergueeva, T. Tamayo, P. Dickerson, A.K. Mukherjee, Mater. Sci. Eng. A 493 (2008) 274. 


\section{Residual stress within nanoscale metallic multilayer systems during thermal cycling}

D. R. Economy ${ }^{\mathrm{a}, *}$, M. J. Cordill ${ }^{\mathrm{b}}$, E. A. Payzant ${ }^{\mathrm{c}}$, M. S. Kennedy ${ }^{\mathrm{a}, \mathrm{d}}$

${ }^{a}$ Department of Materials Science and Engineering, Clemson University, Clemson, SC 29634, USA

${ }^{\mathrm{b}}$ Erich Schmid Institute, Austrian Academy of Sciences and Department of Materialphysik, Montanuniversitaet Leoben, Leoben 8700, Austria

${ }^{\mathrm{c}}$ Center for Nanophase Materials Sciences, Oak Ridge National Laboratory, Oak Ridge, TN 37831, USA

${ }^{\mathrm{d}}$ Center for Optical Materials Science and Engineering Technologies (COMSET), Clemson University, Clemson, SC 29634, USA

* Corresponding author. Tel.: +1 864.722.2107.

E-mail address: deconom@g.clemson.edu (D. R. Economy).

\section{Abstract}

Projected applications for nanoscale metallic multilayers will include wide temperature ranges. Since film residual stress has been known to alter system reliability, stress development within new film structures with high interfacial densities should be characterized to identify potential long-term performance barriers. To understand factors contributing to thermal stress evolution within nanoscale metallic multilayers, stress in $\mathrm{Cu} / \mathrm{Nb}$ systems adhered to $\mathrm{Si}$ substrates was calculated from curvature measurements collected during cycling between $25^{\circ} \mathrm{C}$ and $400{ }^{\circ} \mathrm{C}$. Additionally, stress within each type of component layers was calculated from shifts in the primary peak position from in-situ heated X-ray diffraction. The effects of both film architecture (layer thickness) and layer order in metallic multilayers were tracked and compared with monolithic $\mathrm{Cu}$ and $\mathrm{Nb}$ films (1 $\mu \mathrm{m}$ total thickness). Analysis indicated that the thermoelastic slope of nanoscale metallic multilayer films (with $20 \mathrm{~nm}$ and $100 \mathrm{~nm}$ individual layer thicknesses) depends on thermal expansion mismatch, elastic modulus of the components, and also interfacial density. The layer thickness (i.e. interfacial density) affected thermoelastic slope magnitude $\left(-1.23 \pm 0.09 \mathrm{MPa} /{ }^{\circ} \mathrm{C}\right.$ for $20 \mathrm{~nm} \mathrm{Cu} / \mathrm{Nb}$ vs. $-0.89 \pm 0.03 \mathrm{MPa} /{ }^{\circ} \mathrm{C}$ for $\left.100 \mathrm{~nm} \mathrm{Cu} / \mathrm{Nb}\right)$ while layer order had minimal impact on stress responses after the initial thermal cycle $(-0.82 \pm$ 
For Submission to Materials Science and Engineering A

$0.07 \mathrm{MPa} /{ }^{\circ} \mathrm{C}$ for $100 \mathrm{~nm} \mathrm{Cu} / \mathrm{Nb}$ ). When comparing stress responses of monolithic $\mathrm{Cu}$ and $\mathrm{Nb}$ films to those of the $\mathrm{Cu} / \mathrm{Nb}$ systems, the nanoscale metallic multilayers show a similar increase in stress above $200{ }^{\circ} \mathrm{C}$ to the $\mathrm{Nb}$ monolithic films, indicating that $\mathrm{Nb}$ components play a larger role in stress development than $\mathrm{Cu}$. Phase specific stress calculations ( $\mathrm{Cu}$ vs. $\mathrm{Nb}$ ) from $\mathrm{X}$-ray diffraction peak shifts in $20 \mathrm{~nm} \mathrm{Cu} / \mathrm{Nb}$ collected during heating reveal that the component layers within a multilayer film respond similarly to their monolithic counterparts.

Keywords: Copper-Niobium, Thin films, Nanoscale metallic multilayers, Thermomechanical processing, Residual stresses, Thermal expansion mismatch

\section{Introduction}

To enhance mechanical properties of thin films, research groups have started creating synthetic two-dimensional structures within films by selective deposition of metallic films. One of these such structures that have become prevalent recently are nanoscale metallic multilayers (NMMs). NMMs are composed of alternating metallic layers with nanometer-level $(<100 \mathrm{~nm})$ individual layer thicknesses that have shown superior strength [1-3], radiation damage resistance [4-6], and wear-resistance $[7,8]$ when compared to their monolithic counterparts. These types of layered systems are referred to in many different manners by various researchers including NMMs, nanolaminates, multilayers, herringbone structures, nanoheterostructures, et cetera; however, many of the terms are synonymous. For the purposes of this work, these systems will be referred to as NMMs. In some cases, researchers have observed that these film systems have undergone both microstructural and mechanical instability during heating [9-12]. These 
microstructural and mechanical instabilities in NMM systems have been linked to residual stresses imposed by the substrate during thermal cycling [9-12].

Residual stress can be a significant factor in the response of a material to external stimuli, most notably the magnitudes of diffusion [13,14], deformation [15-17], and optical transmission [18]. This type of stress has been observed in both thin films and bulk metals. In bulk metals, the magnitude of residual stress is often below that of the yield stress level [19]. However, in thin-film systems, residual stresses have been observed to readily exceed $1 \mathrm{GPa}$ in either tension or compression [19]. Intrinsic sources of residual stress in thin films include those due to the system's microstructure, or those originating from defects during film deposition [19]. Extrinsic sources of stress in thin-film systems can include those due to thermal expansion mismatches between the substrate and film constituent materials [19]. When researchers compare the stresses calculated in monolithic films during thermal cycles, they often observe a deviation between the stress hysteresis of the first and subsequent thermal cycles [20-22]. After the initial relief of intrinsic stresses from deposition, the primary source of stress within films during thermal cycling is typically assumed to arise from thermal expansion mismatch between the film and substrate. This study seeks to examine the development of residual stress in $\mathrm{NMM} \mathrm{Cu/Nb}$ films adhered to Si during thermal cycling due to the role of stress on the microstructural instability [9-12]. This work is necessary to further understand the development of residual stresses in NMM film systems to foster their usage in practical settings such as high-strength coatings in extreme temperature environments for energy and defense applications [23].

$\mathrm{Cu} / \mathrm{Nb}$ was chosen as a model system in this study due to its frequency in the literature [2,9,24-27] and because the constituent materials $(\mathrm{Cu}$ and $\mathrm{Nb})$ do not form intermetallic compounds with one another $[23,28]$. To understand the thermal stress response of a composite 
film system, it is necessary to understand the constituents by themselves $[29,30]$. The thermal response of copper films has been studied extensively due to its importance in the microelectronics industry [20,21,31,32]. Thermal stress response in Nb films, however, has not been examined in the literature.

A key parameter to understanding the thermal stress development of films is the elastic (linear) slope of the stress as a function of temperature that can typically be found on cooling, which is known as the thermoelastic slope [22]. This parameter gives an indication of how much stress is being developed from changes in temperature with a greater magnitude indicating greater stress. Keller et al. has described thermoelastic slope of a film, $m$, in monolithic film systems on a substrate as:

$$
m=\left(\frac{E_{f}}{1-v_{f}}\right) \Delta \alpha
$$

where it depends on elastic components: $E_{f}$, elastic modulus of the film and Poisson's ratio of the film, $v_{f}$, and thermal expansion mismatch between the film and substrate, $\Delta \alpha[31]$. Based on predictions using Eq. (1) $\mathrm{Cu} / \mathrm{Nb}$ should have an estimated thermoelastic slope of $-1.8 \mathrm{MPa} /{ }^{\circ} \mathrm{C}$ based on literature values of $\mathrm{CTE}$ for $\mathrm{Cu}, \mathrm{Nb}$, and $\mathrm{Si}$ (using the difference between $\mathrm{Si}$ and a combined mean value for both $\mathrm{Cu}$ and $\mathrm{Nb}$ ) [33,34], approximate elastic modulus from nanoindentation $(125 \mathrm{GPa})$, and an assumed Poisson's ratio $(v \approx 0.37,[35])$.

Only two studies have been found that sought to examine the thermal stress progression for nanoscale multilayer systems $[30,36]$. Windt studied the thermal stress response of multilayer films with sub-10 nm individual layers of Mo, W, Si, and C (also on Si substrates) to examine the role of nanoscale multilayer architecture on thermal stress development [30]. Windt's study did not examine how varying the magnitudes of layer thickness might impact stress, but solely focused on characterizing the difference between sub-10 nm individual layer thickness ( $1 \mathrm{~nm}$ to 
For Submission to Materials Science and Engineering A

$5 \mathrm{~nm}$ ) multilayer films [30]. Similarly, Gram et al. examined the stress responses of $11 \mathrm{~nm}$ and

$21 \mathrm{~nm} \mathrm{Cu} / \mathrm{Ni} \mathrm{NMMs}$ during heating [36]. In Windt's study, it was observed that the varying architectures in either a net tensile or net compressive stress after heating depended on individual layer thickness. This variation in stress response was attributed to the role of interfacial stresses in the systems [30], which are defined as those associated with the layer interfaces (one layer to another) [37]. These stresses have been attributed to local CTE variation [30] and the surface energies assiociated with the interface [37]. The role of interfacial stresses aside from the film/substrate interface in monolithic films and macro-multilayers is negligible due to low interfacial density, but could become appreciable for nanoscale layer thicknesses. Gram et al. identified that there is a separate stress response in the component layers $(\mathrm{Cu}$ versus $\mathrm{Ni})$, as was shown with in-situ heated XRD, and that the thicker $21 \mathrm{~nm}$ layered system showed greater deviation from the predicted thermoelastic slope [36].

In this study stress was approximated in two separate contexts; first to estimate the residual stress developed during deposition (how the substrate changes before and after the film is initially deposited) to serve as starting values for the study. Second, the curvature was monitored continuously throughout a thermal cycle in two different in-situ systems, substrate curvature and $\mathrm{XRD}$, to show the progression of thermal stress during heating and cooling. This complimentary approach to examining stress response allowed for the determination of differences between the phase specific stress and the composite stress in the $\mathrm{Cu} / \mathrm{Nb} \mathrm{NMM}$ architecture (phase specific: $\mathrm{Cu}$ or $\mathrm{Nb}$ vs. composite: $\mathrm{Cu}$ and $\mathrm{Nb}$ ).

\section{Experimental methods}




\subsection{Fabrication of thin film systems}

$\mathrm{Cu} / \mathrm{Nb} \mathrm{NMM}$ and monolithic $\mathrm{Cu}$ and $\mathrm{Nb}$ films were deposited to examine the influence of film architecture and geometry on residual stress development during thermal cycling. All films were deposited on (100) Si substrates (350-400 $\mu \mathrm{m}$ thickness) using a Kurt J. Lesker sputter deposition system using a process detailed previously [9]. The deposition rates obtained were $4.0 \mathrm{~nm} / \mathrm{min}$ for $\mathrm{Cu}$ and $2.9 \mathrm{~nm} / \mathrm{min}$ for $\mathrm{Nb}$. Six types of samples were deposited for this study, $20 \mathrm{~nm} \mathrm{Cu} / \mathrm{Nb}, 20 \mathrm{~nm} \mathrm{Nb} / \mathrm{Cu}$ (50 total layers), $100 \mathrm{~nm} \mathrm{Cu} / \mathrm{Nb}, 100 \mathrm{~nm} \mathrm{Nb} / \mathrm{Cu}$ (10 total layers), as well as monolithic $\mathrm{Cu}$ and $\mathrm{Nb}$ films. In all films the total thickness was kept constant at $1 \mu \mathrm{m}$. The two different notations for the NMM systems $(\mathrm{Cu} / \mathrm{Nb}$ and $\mathrm{Nb} / \mathrm{Cu})$ indicate the layer order (geometry) with $\mathrm{Cu} / \mathrm{Nb}$ having the $\mathrm{Cu}$ layer deposited first and $\mathrm{Nb}$ layer deposited subsequently, and the reverse for the $\mathrm{Nb} / \mathrm{Cu}$ samples. The two different geometries were used to examine the influence of the base layer on the stress development. Additionally, the monolithic $\mathrm{Cu}$ film contained an $\mathrm{Nb}$ adhesion layer (approximate thickness: $5 \mathrm{~nm}$ ). A matrix of the samples produced for this study is included in Table 1.

\section{Table 1}

Film systems produced for studying the effects of architecture and geometry on performance during and after thermal cycling.

\begin{tabular}{cccc}
\hline & \multicolumn{3}{c}{ Layer Geometry } \\
\cline { 2 - 4 } & $\mathrm{Cu} / \mathrm{Nb} \mathrm{NMM} \mathrm{Systems}$ & $\mathrm{Nb} / \mathrm{Cu} \mathrm{NMM}$ Systems & Monolithic Systems \\
\hline Layer & $20 \mathrm{~nm} \mathrm{Cu} / \mathrm{Nb}$ & $20 \mathrm{~nm} \mathrm{Nb} / \mathrm{Cu}$ & $1 \mu \mathrm{m} \mathrm{Cu}$ \\
Architecture & $100 \mathrm{~nm} \mathrm{Cu} / \mathrm{Nb}$ & $100 \mathrm{~nm} \mathrm{Nb} / \mathrm{Cu}$ & $1 \mu \mathrm{m} \mathrm{Nb}$ \\
\hline \multicolumn{3}{c}{ Total thickness of each system was $1 \mu \mathrm{m}$} \\
\hline
\end{tabular}

\subsection{Characterization methods}

As-deposited film residual stress (due to deposition parameters) was calculated using the changes in substrate curvature before and after film deposition as measured by stylus 
For Submission to Materials Science and Engineering A

profilometry (Veeco Dektak ${ }^{3}$ ). This curvature was measured using $20 \mathrm{~mm}$ line scans, with seven radial measurements taken per sample both before and after deposition. These measurements were then used along with the constraints imposed by the Si substrate [38] to calculate residual stress using Stoney's equation [39].

Additionally, initial hardness was calculated from nanoindentation load-displacement measurements with a three-sided diamond Berkovich indentation probe $\left(E_{\text {Diamond }}\right.$ : $1140 \mathrm{GPa}$, $v_{\text {Diamond }} 0.07$ [15]). Each sample was indented a minimum of 24 times, four indents each at six maximum depths between $100 \mathrm{~nm}$ and $75 \mathrm{~nm}$, using the displacement-controlled indentation mode on a Hysitron Triboscope system. Nanoindentation data analysis was performed in accordance with the Oliver-Pharr method [40]. The Triboscope system was calibrated using fused quartz immediately prior to testing $\left(E_{\mathrm{R}}: 69.6 \mathrm{GPa}, H: \approx 9 \mathrm{GPa}\right)[15]$.

Mechanical, microstructural (morphology and grain growth), and chemical (formation of new phase) changes were characterized following thermal cycling using nanoindentation, electron backscatter diffraction (EBSD), atomic force microscopy (AFM), and X-ray diffraction (XRD). EBSD was performed using an EDAX Inc. system, which was integrated into a LEO 1525 fieldemission-gun scanning electron microscope (SEM). The in-plane grain size of the top film layers were calculated by the line intercept method using one-micrometer square images of each sample taken by a Digital Instruments Dimension AFM in tapping mode. Additional structural and chemical characterization was carried out using XRD on a Rigaku SmartLab four-circle diffractometer. 


\subsection{Stress approximation in thin films}

In this study, biaxial film stress was approximated by measuring changes in substrate curvature and calculated using a modified form of Stoney's equation [19,39]:

$$
\sigma_{f}=\frac{M_{s} t_{s}^{2}}{6\left(1-v_{s}\right) t_{f}}\left(\frac{1}{R_{\text {final }}}-\frac{1}{R_{\text {initial }}}\right)
$$

where $M_{s}$ is biaxial elastic modulus of substrate [(100) Si for the purposes of this study], $t_{s}$ is the substrate thickness, $t_{f}$ is film thickness, $v_{s}$ is the Poisson ratio of the substrate (0.28 for Si [38]) and $R_{\text {final }}$ and $R_{\text {initial }}$ are the final and initial radii of curvature of the substrate respectively. This relation uses a thin film, thick substrate approximation $\left(t_{f}<t_{s}\right)$, practically assuming that the curvature change is governed solely by the mechanical properties of the substrate as can be seen in Eq. (2).

\subsection{In-situ measurement of residual stress during thermal cycling}

The in-situ substrate curvature measurement system used in this study is a custom-built instrument at the Erich Schmid Institute of Materials Science in Leoben, Austria. The system is comprised of a vacuum chamber, an Edwards turbomolecular pump, a ceramic resistance heater, and a kSA Multi-beam Optical Sensor (MOS) in-situ stress monitoring system. The kSA MOS system utilizes a series of parallel mirrors (etalons) to split the laser beam into 16 diffracted spots into a four $\times$ four-spot matrix allowing curvature measurement in both horizontal and vertical directions. The kSA MOS system was calibrated using reference mirrors [an optical flat and a concave mirror (radius: $10 \mathrm{~m}$ ) from Edmund Optics].

Samples were subjected to a temperature cycle between $25{ }^{\circ} \mathrm{C}$ and $400{ }^{\circ} \mathrm{C}$ using a heating rate of $10{ }^{\circ} \mathrm{C} / \mathrm{min}$ and a minimum vacuum of $7.5 \times 10^{-5}$ Torr. Upon reaching the maximum temperature, the samples were held at $400{ }^{\circ} \mathrm{C}$ for 40 minutes, then allowed to cool to room 
temperature. The system did not include any means for active cooling. The cooling rate was not controlled and resulted in an average cooling rate of $\approx 6.9{ }^{\circ} \mathrm{C} / \mathrm{min}$. Each individual, single-cycle test took approximately three hours in total. A maximum temperature of $400{ }^{\circ} \mathrm{C}$ was chosen for consistency with previous work studying $\mathrm{Cu} / \mathrm{Nb} \mathrm{NMM}$ systems adhered to silicon substrates [9]. Additional three-cycle tests were performed with an identical first cycle to the single cycle tests; the following two cycles were similar but isothermal holds were reduced to five minutes and the minimum temperature reached between cycles was $40{ }^{\circ} \mathrm{C}$. It has been established that the primary stress responses that occur during a deposited film's first heating cycle are irreversible, often due to the relief of defects formed during deposition and microstructural evolution [20,21]. Thus, the stress behaviors in the film on the first cycle are not indicative of future stress evolution. As such, it is necessary to study the stress progression in films through multiple cycles to examine both the initial changes as well as the stress behavior after those initial fluctuations have occurred. Thermal cycling stress tests were conducted under vacuum (< $7.5 \times 10^{-5}$ Torr). A representative thermal and stress profile for a three-cycle test can be seen in Fig. 1. Repeatability of the cyclic stress behaviors were ascertained by performing these tests two to three times on each sample type.

\section{A)}

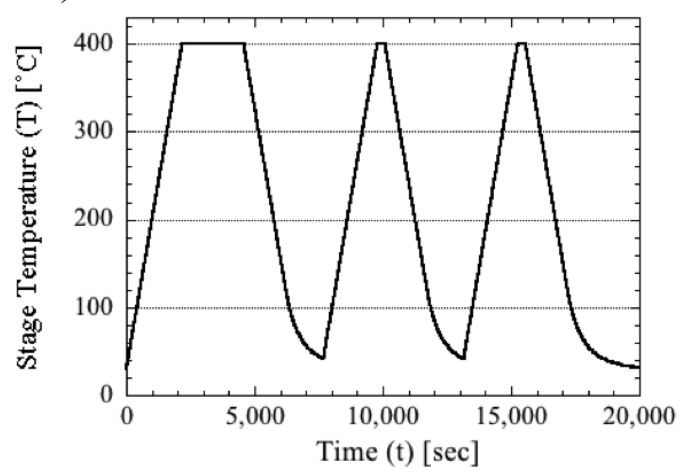

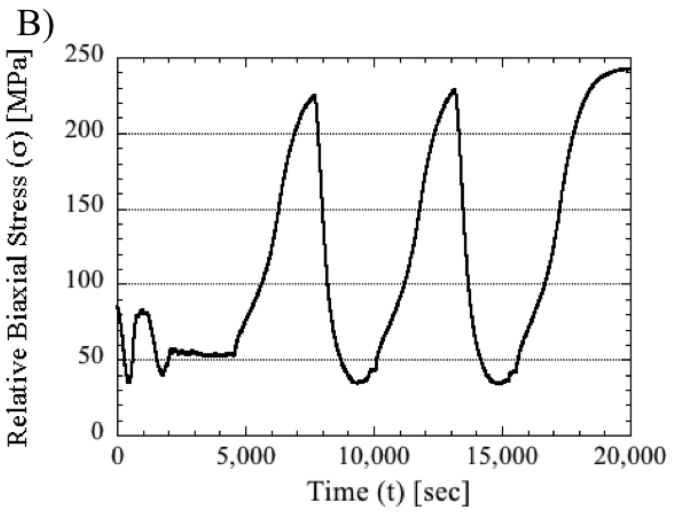

Fig. 1. A) Temperature and B) stress profiles during the progression of a representative threecycle curvature measurement test on $\mathrm{Cu} / \mathrm{Nb} \mathrm{NMM}$ systems. 
To further examine the development of residual stress in NMM systems a complimentary XRD measurement technique was used to further validate the curvature measurements. Component dependent stress in $\mathrm{NMM} \mathrm{Cu} / \mathrm{Nb}$ has been measured through the use of in-situ heated XRD. A PANalytical X'Pert Pro MRD four-circle diffractometer equipped with an Anton-Paar DHS-900 digital hot stage was used for these measurements. Stress was calculated from deviations of primary peak position measurements [Cu (111) and $\mathrm{Nb}(110)]$ from their equilibrium positions. These peak spacings were measured using a short two- $\theta$ scan while at high $\chi$ tilt $\left(85^{\circ}\right)$ to measure the in-plane direction with respect to the film, using a method similar to that previously described by Gram et al. [36]. Measurements were taken from room temperature to $400{ }^{\circ} \mathrm{C}$ in $50{ }^{\circ} \mathrm{C}$ increments during isothermal holds. Previous researchers have shown that stress measurements using both curvature and X-ray determination methods yield complimentary results for monolithic film systems [41,42].

The local lattice strain obtained from changes in primary peak spacing is material dependent, meaning that the strain values obtained are an average for all of the $\mathrm{Cu}$ layers and all of the $\mathrm{Nb}$ layers independently. Lattice strain, $\epsilon$, is given by:

$$
\epsilon(T)=\ln \left(\frac{d(T)}{d_{0}(T)}\right)
$$

where $d(T)$ is the measured lattice parameter (strained) and $d_{0}(T)$ is the stress free lattice parameter after accounting for thermal expansion determined by:

$$
d_{0}(T)=d_{0}\left(25^{\circ} C\right)+\alpha * \Delta T
$$

where $d_{0}\left(25^{\circ} \mathrm{C}\right)$ is the room temperature stress free lattice parameter taken from star quality ICCD PDF cards, $\alpha$ is the coefficient of thermal expansion (CTE) taken from the literature $[33,34]$, and $\Delta T$ is the change in temperature with respect to $25{ }^{\circ} \mathrm{C}$. Lattice stress was calculated 
using linear elastic theory and the temperature dependent elastic constants $[43,44]$ to accommodate for the compliance of that particular crystalline direction $[\mathrm{Cu}(111)$ and $\mathrm{Nb}(110)]$ given by:

$$
E_{111}(T)=S_{11}(T)-\frac{2}{3}\left(\left(S_{11}(T)-S_{12}(T)\right)-\frac{S_{44}(T)}{2}\right)
$$

and:

$$
E_{110}(T)=S_{11}(T)-\frac{1}{2}\left(\left(S_{11}(T)-S_{12}(T)\right)-\frac{S_{44}(T)}{2}\right)
$$

where $S_{i j}(T)$ are the specific temperature-dependent compliance matrix components to determine the directional modulus as detailed by Hopcroft et al. [38]. Using the lattice strain $[\epsilon(T)]$ and the elastic modulus $\left[\left(E_{h k l}(T)\right]\right.$ the peak shifting stress was computed by:

$$
\sigma(T)=\epsilon(T) * E_{h k l}(T)
$$

assuming elastic strains, linear dependence of CTE and elastic constants with respect to temperature, and results in an average value for all of the layers of a single component $(\mathrm{Cu}$ versus $\mathrm{Nb}$ ). This heating was performed under vacuum through the use of a mechanical roughing pump, however, there were no means to measure the pressure obtained.

\section{Results and discussion}

\subsection{Initial properties of monolithic and NMM systems}

The NMM film systems contained varying amounts of initial residual stress, which are summarized in Fig. 2. Stresses were observed to range from $420 \mathrm{MPa}$ in tension to $620 \mathrm{MPa}$ in compression (Fig. 2). Compressive stresses are denoted by negative values. Samples are also included that had been deposited 14 months prior (2/2013) using the same deposition parameters. It is important to note that stresses in the samples deposited in 2/2013 were measured immediately following deposition. Since room temperature stress relief (up to 25\%) has been 
observed for $\mathrm{Mo} / \mathrm{Si}$ multilayer systems over a period of six months, these values may be overestimates [30]. For reference, the monolithic film systems and most of the NMM films were deposited just prior to the stress examination (4/2014).
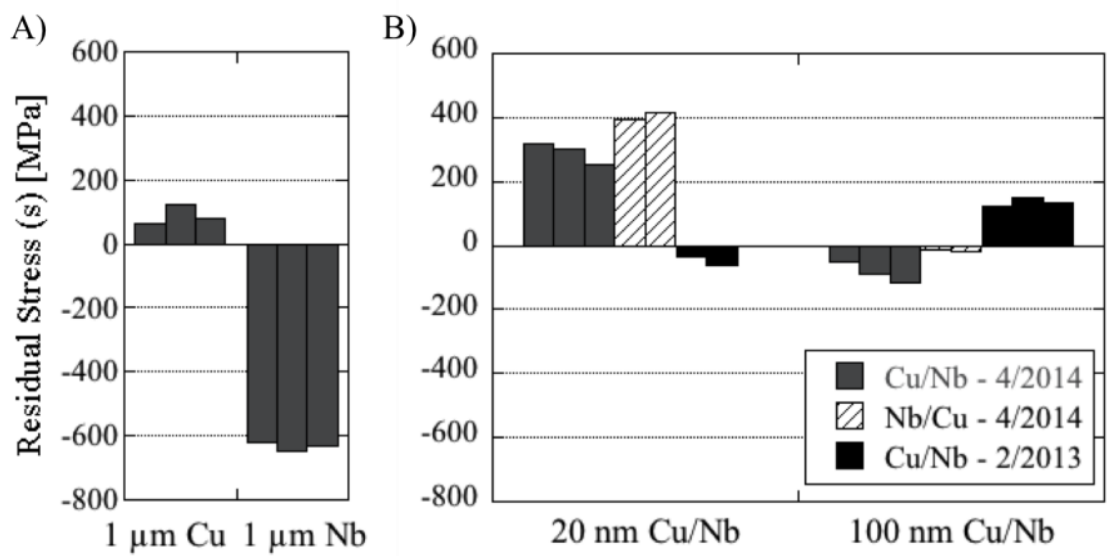

Fig. 2. Initial residual stresses of film systems for this study including (A) monolithic films and (B) NMM architectures as calculated from changes in substrate curvature. Residual stress can depend on several factors including deposition conditions, lifetime of source target, and sample history. Dates in legend indicate the date of fabrication.

Other properties of the systems produced for this study are in agreement with values expected from the literature. The as-deposited hardness values measured for monolithic films $\left(H_{\mathrm{Cu}}: 2.4 \pm 0.2 \mathrm{GPa}, H_{\mathrm{Nb}}: 5.4 \pm 0.5 \mathrm{GPa}\right)$ were consistent with both the values seen in literature for $\mathrm{Cu}(H: 2.3 \pm 0.2 \mathrm{GPa}[45])$ and $\mathrm{Nb}(H: \approx 4 \mathrm{GPa}[46])$. The monolithic film hardness measurements were also similar with those measured for the NMM systems for this study $(H: 5.2$ \pm 0.2 for $20 \mathrm{~nm} \mathrm{Cu} / \mathrm{Nb}$, and $H: 4.4 \pm 0.2 \mathrm{GPa}$ for $100 \mathrm{~nm} \mathrm{Cu} / \mathrm{Nb}$ ) and those in literature [2,9]. It was observed that for both the $\mathrm{Cu} / \mathrm{Nb}$ and $\mathrm{Nb} / \mathrm{Cu}$ geometries, hardness of the $\mathrm{NMM}$ systems increase as individual layer thickness is reduced [1]. Primary orientations for both $\mathrm{Cu}(111)$ and $\mathrm{Nb}$ (110) were observed by XRD. It is noted that in some instances, the diffraction peaks were significantly shifted from indexed positions, indicative of the stresses contained in the system. 
For Submission to Materials Science and Engineering A

The primary orientations observed are consistent with the Kurdjumov-Sachs orientation relationship that has been identified for $\mathrm{Cu} / \mathrm{Nb}$ NMM systems $\left[(111)_{\mathrm{Cu}(\mathrm{FCC})} \|(110)_{\mathrm{Nb}(\mathrm{BCC})}\right][47]$.

\subsection{Progression of residual stresses in monolithic films developed during thermal cycling}

As the films are heated, the components ( $\mathrm{Cu}$ film, $\mathrm{Nb}$ film, Si substrate) expand at different rates due to CTE mismatch. This varying expansion will create stress due to the confinement of the film by the substrate. CTEs for the primary components in this study are $1.65 \times 10^{-5} \mathrm{~K}^{-1}$, $7.3 \times 10^{-6} \mathrm{~K}^{-1}$, and $2.6 \times 10^{-6} \mathrm{~K}^{-1}$ for $\mathrm{Cu}, \mathrm{Nb}$, and $\mathrm{Si}$ respectively at room temperature [33,34]. It should be noted that $\mathrm{CTE}$ values are temperature dependent, but for $\mathrm{Cu}, \mathrm{Nb}$, and $\mathrm{Si}, \mathrm{Cu}$ has been shown to have the greatest value and $\mathrm{Si}$ has the least at all temperatures examined $\left(25^{\circ} \mathrm{C}\right.$ to 400 $\left.{ }^{\circ} \mathrm{C}\right)[33,34]$. By again measuring how the substrate curvature varies (as a function of temperature) through the course of a heating cycle, residual stress can be approximated for the film. The initial residual stress value determined from change in substrate curvature during deposition (Fig. 2) was used as the starting residual stress in the in-situ testing.

The initial tensile stress of the $\mathrm{Cu}$ film decreases from room temperature to $100{ }^{\circ} \mathrm{C}$, at which point the stress then increases [Fig. 3 (A) \& (B)]. Above $200{ }^{\circ} \mathrm{C}$ the stress plateaus, followed by a secondary decrease until approximately $330{ }^{\circ} \mathrm{C}$, where the stress begins to increase again. The increase in stress above $330{ }^{\circ} \mathrm{C}$ continues through the remaining heating portion, during the isothermal hold at $400{ }^{\circ} \mathrm{C}$ and throughout the entire cooling segment until room temperature. The stress behavior on initial heating [Fig. 3(B)] follows a similar stress progression with previously published results for monolithic $\mathrm{Cu}$ films [20]. Proposed mechanisms for these stress changes have been suggested to include the relief of defects due to film fabrication, the removal of Ar atoms embedded during deposition, and grain growth [20]. 

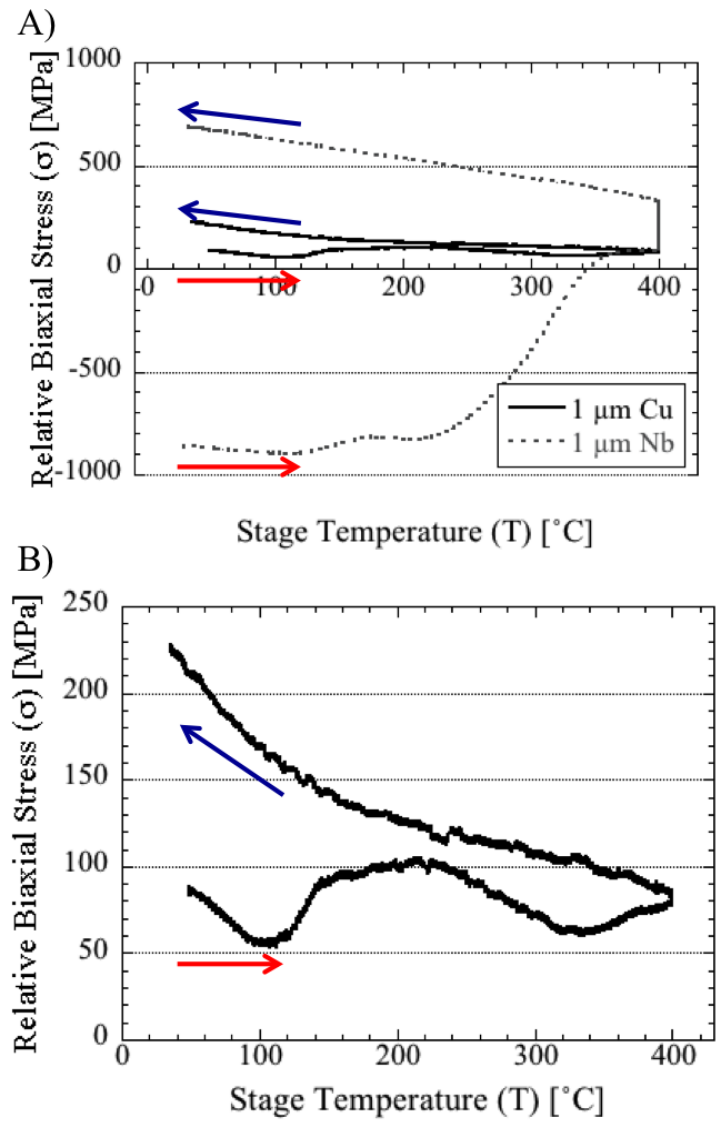

Fig. 3. Development of stress in A) one micrometer thick monolithic films a single heating cycle, with $\mathrm{B}$ ) showing a magnified scale of the monolithic $\mathrm{Cu}$ film by itself. Multiple changes in inflection are indicative of multiple mechanisms for stress evolution. Arrows indicate heating (red) and cooling (blue) segments. Initially compressive stress in the $\mathrm{Nb}$ system becomes largely tensile $(\approx 500 \mathrm{MPa})$ after the initial cycle while the stress in the $\mathrm{Cu}$ film remains modest throughout $(<200 \mathrm{MPa})$.

The stress progression in monolithic $\mathrm{Cu}$ greatly contrasts the behavior observed in $\mathrm{Nb}$ film during heating [Fig. 3(A)]. The stress evolution observed in the $\mathrm{Nb}$ film is largely consistent with behavior noted in other BCC metals published elsewhere [30]. The large initial compressive stress in the $\mathrm{Nb}$ remains mostly unchanged during heating until above $200{ }^{\circ} \mathrm{C}$, at which point it rapidly becomes tensile. During the isothermal hold, the stress increases. The stress also increases linearly during cooling. The thermoelastic slope can be extracted from these tests as the slope of the linear portions of the cooling curves [31], for $\mathrm{Nb}$ this is for temperatures 
For Submission to Materials Science and Engineering A

below $350{ }^{\circ} \mathrm{C}$ and for $\mathrm{Cu}$ this is for $\mathrm{T}<100{ }^{\circ} \mathrm{C}$. The calculated values are in accordance with accepted CTEs with respect to the Si substrate [33,34]. The overall difference in magnitude of stress might be expected due to the large difference in homologous temperature ranges used, a factor of the different melting temperatures of the films; $\mathrm{Cu}$, a relatively low melting metal and $\mathrm{Nb}$, which is a refractory metal $\left[1085^{\circ} \mathrm{C}(1358 \mathrm{~K})\right.$ and $2469^{\circ} \mathrm{C}(2742 \mathrm{~K})$, respectively].

When the monolithic films were subjected to multiple cycle tests, similar stress results were observed for the first heating and cooling cycles [Fig. 4(A)]. After the initial heating above the deposition temperature, many of the sputter-induced defects are relieved, and all of the films progress toward tensile stresses [20]. The second and third heating cycles on $\mathrm{Cu}$ films show hysteresis [Fig. 4(B)], which is consistent with what other researchers have shown for multiple thermal cycles [20]. At lower temperatures, the stress response is primarily linear, but above 100 ${ }^{\circ} \mathrm{C}$ the heating and cooling portions deviate. The stress on heating decreases to levels achieved on the initial heating step $(<50 \mathrm{MPa})$.

Conversely, monolithic Nb films do not show significant hysteresis [Fig. 4(A)]. After the large shift toward tensile stress in the first cycle, further stress progression is largely linear. Above $350{ }^{\circ} \mathrm{C}$, the response is nonlinear. During the isothermal holds at $400{ }^{\circ} \mathrm{C}$, the stress continues to increase, indicating a possible high temperature reaction that has not yet reached completion. It is noted that the thermoelastic slopes on subsequent heating and cooling are within experimental error as compared to the initial cooling from $400{ }^{\circ} \mathrm{C}\left(m_{\mathrm{Cu}}:-0.84 \pm 0.11\right.$ $\left.\mathrm{MPa} /{ }^{\circ} \mathrm{C}, m_{\mathrm{Nb}}:-0.62 \pm 0.02 \mathrm{MPa} /{ }^{\circ} \mathrm{C}\right)$. 

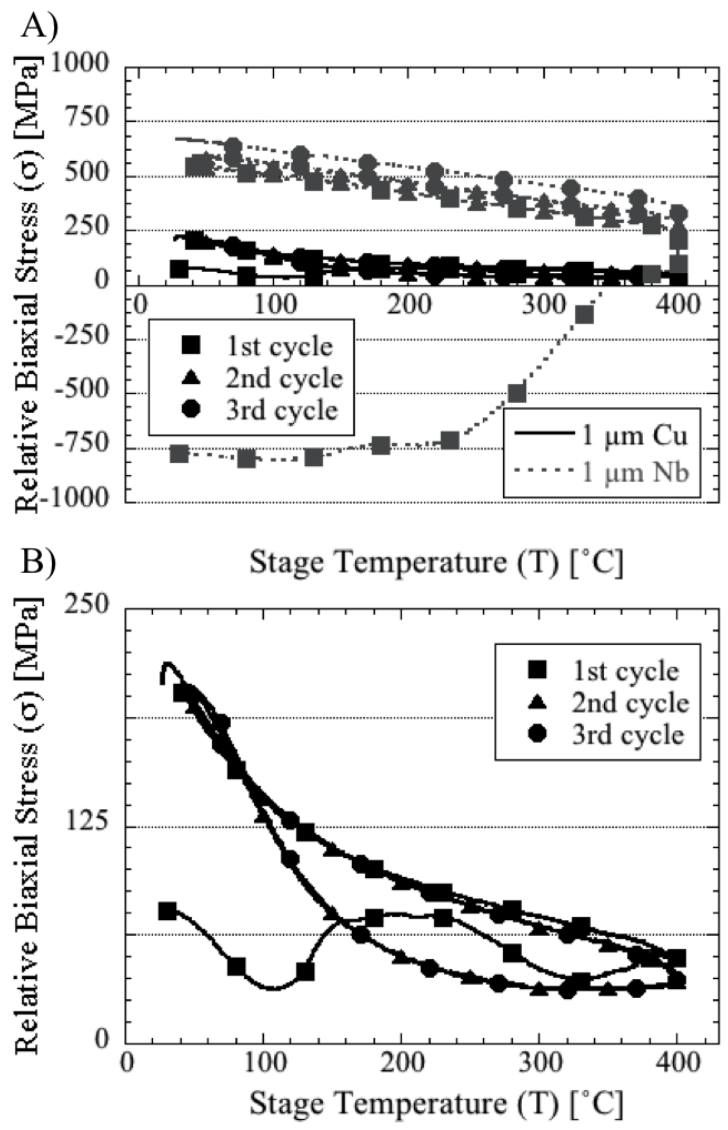

Fig. 4. Development of stress in A) one micrometer monolithic films during three heating cycles, with $\mathrm{B}$ ) showing a magnified scale of the monolithic $\mathrm{Cu}$ film by itself. The inflection changes noted on the initial heating are absent in following heating cycles. The hysteresis observed is consistent with those observed by other researchers for $\mathrm{Cu}$ films on $\mathrm{Si}$ [20]. The subsequent changes in $\mathrm{Nb}$ stress after the first cycle occur at temperatures $\approx 400{ }^{\circ} \mathrm{C}$, otherwise similar to the initial cooling step (similar slope).

\subsection{Progression of residual stresses in NMM systems developed during thermal cycling}

When NMM systems are heated, stress progressions have been observed that are comparable to the $\mathrm{Nb}$ stress response [Fig. 3(A)]. For the $20 \mathrm{~nm} \mathrm{Cu} / \mathrm{Nb}$ system, the initial tensile stress decreases upon heating from room temperature to $360{ }^{\circ} \mathrm{C}$ (Fig. 5). During the isothermal hold at $400{ }^{\circ} \mathrm{C}$, the stress continues to decrease and on cooling it linearly increases. 


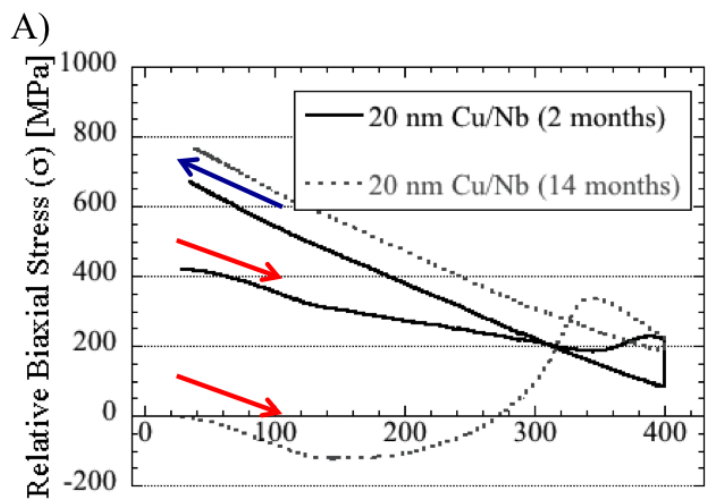

B)

Stage Temperature $(\mathrm{T})\left[{ }^{\circ} \mathrm{C}\right]$

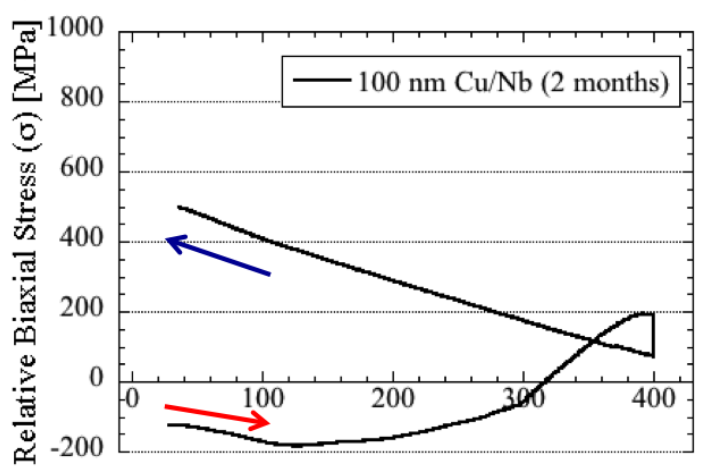

Stage Temperature $(\mathrm{T})\left[{ }^{\circ} \mathrm{C}\right]$

Fig. 5. Comparison of differing samples (architectures) on stress progression with similar temperature profiles: A) $20 \mathrm{~nm} \mathrm{Cu} / \mathrm{Nb} \mathrm{NMM}$ and B) $100 \mathrm{~nm} \mathrm{Cu} / \mathrm{Nb} \mathrm{NMM}$. In all cases the initial linear portion during heating $\left(<100{ }^{\circ} \mathrm{C}\right)$ gives way to nonlinearity, partial stress relief is observed during the isothermal hold at the maximum temperature followed by the persistence and growth of tensile stresses on cooling. Plastic behavior on heating is distinct for all samples, but linear region on cooling is consistent for specific layer thicknesses. Arrows indicate heating (red) and cooling (blue) segments.

A $20 \mathrm{~nm} \mathrm{Cu} / \mathrm{Nb} \mathrm{NMM}$ sample was deposited and then stored for 14 months. It was then tested in an identical fashion to the other NMM films (Fig. 5). The stresses developed were similar to the progression observed for monolithic $\mathrm{Nb}$ films [Fig. 3(A)]. Upon heating, the stress becomes initially more compressive followed by a large increase above $200{ }^{\circ} \mathrm{C}$. Around $350{ }^{\circ} \mathrm{C}$, the tensile stress decreases, this decrease in stress continues through the isothermal hold at 400 ${ }^{\circ} \mathrm{C}$. On cooling, the tensile stress increases linearly. 
For Submission to Materials Science and Engineering A

This behavior is also seen for the $100 \mathrm{~nm} \mathrm{Cu} / \mathrm{Nb}$ system (Fig. 5). The most notable differences between the two tests $(100 \mathrm{~nm} \mathrm{Cu} / \mathrm{Nb} \mathrm{NMM}$ and $20 \mathrm{~nm} \mathrm{Cu} / \mathrm{Nb} \mathrm{NMM}$ that was deposited 14 month prior) are that the onset of stress relief at high temperatures does not begin until $400{ }^{\circ} \mathrm{C}$ for the $100 \mathrm{~nm}$ system and the $20 \mathrm{~nm}$ system has a larger overall net change in stress (550 MPa for $20 \mathrm{~nm}$ vs. $450 \mathrm{MPa}$ for $100 \mathrm{~nm}$ ). Both of these systems began with initially compressive stresses whereas the newly deposited $20 \mathrm{~nm}$ system had a tensile stress of $300 \mathrm{MPa}$ at the beginning of the test.

It can be seen that despite the large preliminary gap from deposition stresses between the older and newer $20 \mathrm{~nm}$ system, upon initial heating $\left(<150{ }^{\circ} \mathrm{C}\right)$ they both show a similar rate of change $\left(m:-1.23 \pm 0.09 \mathrm{MPa} /{ }^{\circ} \mathrm{C}\right.$ for the $20 \mathrm{~nm}$ sample after two months vs. $-1.28 \mathrm{MPa} /{ }^{\circ} \mathrm{C}$ for the $20 \mathrm{~nm}$ sample after 14 months). Additionally, during cooling both $20 \mathrm{~nm}$ geometries show similar responses, the two curves are parallel for the entirety of the cooling segment. Even though their initial stress states were more than $300 \mathrm{MPa}$ apart, their final stresses after heating to $400{ }^{\circ} \mathrm{C}$ and cooling to room temperature are within $100 \mathrm{MPa}$. This is not observed for the 100 $\mathrm{nm}$ system; although the $100 \mathrm{~nm}$ system displays a similar hysteresis to the older $20 \mathrm{~nm}$ sample, the slopes on initial heating and cooling are dissimilar. This highlights the importance of the NMM architecture over the initial stress conditions imposed by deposition. Additionally, some researchers have mitigated the first cycle effect by short annealing steps prior to their thermal cycling stress measurements [20].

Comparing the stresses developed in the NMM geometries (Fig. 5) with those observed in monolithic $\mathrm{Nb}$ (Fig. 3), one key difference is noted. A new peak is observed at approximately $350{ }^{\circ} \mathrm{C}$ to $400{ }^{\circ} \mathrm{C}$ in $\mathrm{NMM}$ systems (Fig. 5). It is hypothesized that the overall maximum stress achievable in the NMM systems at high temperatures is limited by the high-temperature yield 
For Submission to Materials Science and Engineering A

strength of the $\mathrm{Cu}$ layers. Other researchers have measured the hot-hardness of $\mathrm{Cu}$ to be below 1 $\mathrm{GPa}$ at $400{ }^{\circ} \mathrm{C}$ [48]. The decreased yield strength of $\mathrm{Cu}$ layers combined with the high stress of the $\mathrm{Nb}$ layers would indicate that yielding may occur due to the stresses measured in NMMs at high temperature. However, this would be limited to the $\mathrm{Cu}$ components of the $\mathrm{NMMs}$ as $\mathrm{Nb}$ has a much greater melting temperature $\left[1085{ }^{\circ} \mathrm{C}(1358 \mathrm{~K})\right.$ and $2469{ }^{\circ} \mathrm{C}(2742 \mathrm{~K})$ for $\mathrm{Cu}$ and $\mathrm{Nb}$, respectively].

The CTE mismatch that is often considered of importance is between that of the substrate and the film in contact with the substrate. NMM geometries with opposing geometries (both $\mathrm{Cu}$ and $\mathrm{Nb}$ as base layers) were utilized in order to examine the importance of layer order on stress development. Aside from the layer order, the sample architectures were equivalent.

The NMM systems with $\mathrm{Cu}$ as the base layer were presented in Fig. 5 and are included here for comparison. For both layer thicknesses examined (20 nm [Fig. 6(A)] and $100 \mathrm{~nm}$ [Fig. 6(B)]) the $\mathrm{Nb} / \mathrm{Cu}$ stress evolution is similar to what was observed for the $\mathrm{Cu} / \mathrm{Nb}$ systems (Table 2). Two key deviations were observed: the onset of the peak on heating occurs at lower temperatures, and there is a larger variation in stress. For the $\mathrm{Cu} / \mathrm{Nb}$ systems the stress reaches a peak at approximately $400{ }^{\circ} \mathrm{C}$. However for the $\mathrm{Nb} / \mathrm{Cu}$ systems, this peak is observed between $300{ }^{\circ} \mathrm{C}$ and $350{ }^{\circ} \mathrm{C}$ [Fig. 6 (A) \& (B)]. Most notable is that the slopes on cooling are equivalent for the different layer orders.

\section{Table 2}

Calculated thermoelastic slope values for NMM systems taken from linear regressions during cooling.

\begin{tabular}{ccc}
\hline Layer & \multicolumn{2}{c}{ Layer Geometry } \\
\cline { 2 - 3 } Architecture & $\mathrm{Cu} / \mathrm{Nb}$ NMM Systems & $\mathrm{Nb} / \mathrm{Cu}$ NMM Systems \\
\hline $20 \mathrm{~nm}$ & $-1.23 \pm 0.09 \mathrm{MPa} /{ }^{\circ} \mathrm{C}$ & $-1.11 \pm 0.09 \mathrm{MPa} /{ }^{\circ} \mathrm{C}$ \\
$100 \mathrm{~nm}$ & $-0.89 \pm 0.03 \mathrm{MPa} /{ }^{\circ} \mathrm{C}$ & $-0.82 \pm 0.07 \mathrm{MPa} /{ }^{\circ} \mathrm{C}$ \\
\hline
\end{tabular}



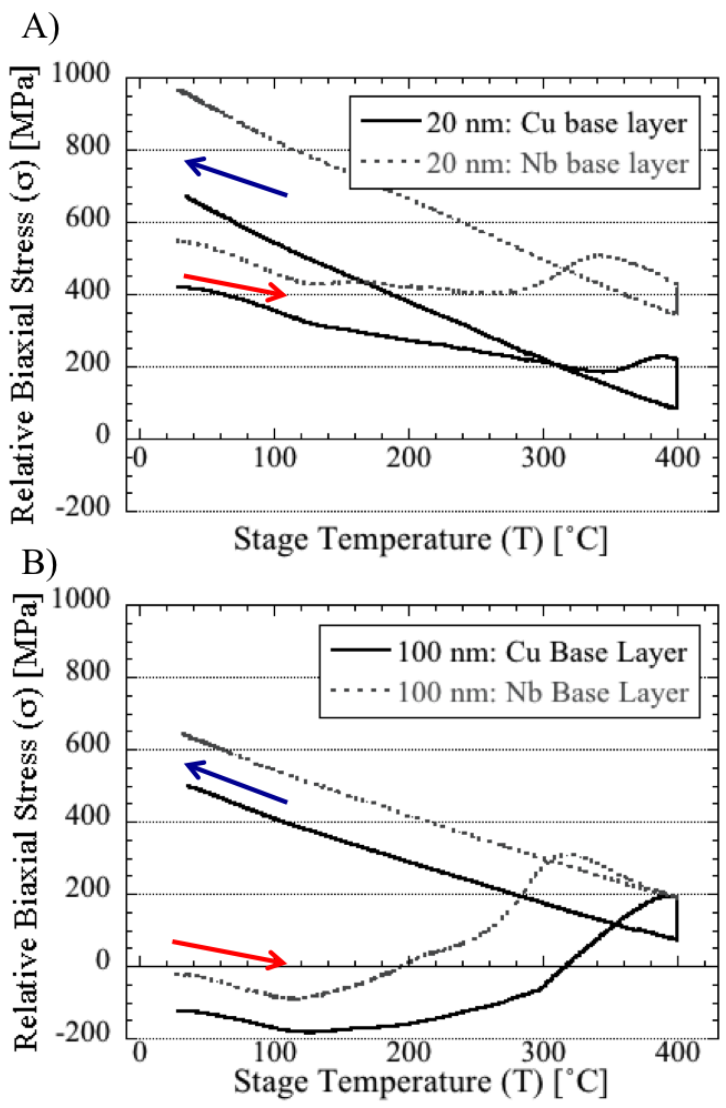

Fig. 6. Comparisons of (A) $20 \mathrm{~nm}$ and (B) $100 \mathrm{~nm} \mathrm{Nb} / \mathrm{Cu}$ (Nb film as a base layer) with similar $\mathrm{Cu} / \mathrm{Nb}$ systems showing the effect of layer order on development of stress during heating to 400 ${ }^{\circ} \mathrm{C}$. A larger stress is developed for the system with $\mathrm{Nb}$ as a base layer with more pronounced features, however the slopes of the linear regions during cooling are consistent for specific layer thicknesses.

A t-test comparing the slope values for the 20 and $100 \mathrm{~nm}$ including both $\mathrm{Cu} / \mathrm{Nb}$ and $\mathrm{Nb} / \mathrm{Cu}$ geometries indicates that there is a significant difference with respect to layer thickness ( $\mathrm{p}$-value: $>0.001$ ). By compiling the thermoelastic slope values (Table 2) for all of the linear portions of the cooling curves for the tests performed into a graph (shown in Fig. 7), it is seen that as layer thickness is reduced, the thermoelastic slope becomes more negative. This means that in NMM systems, thinner layers will develop greater tensile stresses during cooling in the thickness range that has been examined. This relationship also includes the results from stress measurements of 2 
$\mathrm{nm} \mathrm{Cu} / \mathrm{Nb} \mathrm{NMM}$ system with a total thickness of $10 \mu \mathrm{m}$. Poor adhesion resulted in these tests failing and delaminating before completion of the thermal cycle. However, the thermoelastic slope could still be determined from the limited test of the $2 \mathrm{~nm} \mathrm{Cu} / \mathrm{Nb} \mathrm{NMM}$ system.

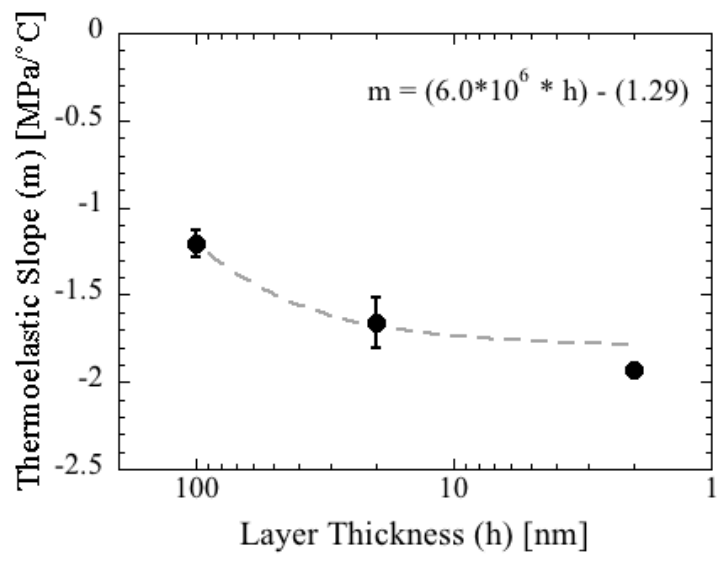

Fig. 7. Thermoelastic slope of varying NMM architectures. Systems with thinner layers have more negative values indicating that more thermal stresses are developed. This is suggested to be due to the increased impact of interfacial stresses, which are omitted in established models.

Traditional descriptions of estimations of the thermoelastic slope do not include terms that would account for changes in layer thickness [31]. It might be suggested that the layer thickness dependent behavior becomes appreciable when the interfacial density becomes significant enough $(\mathrm{h}<\approx 100 \mathrm{~nm})$ to allow for interfacial stress dependent phenomenon to occur. As the layer thickness is further reduced, the thermoelastic slope becomes more negative until a minimum is reached, where the layered structure becomes so thin that layer continuity is an issue. An initial linear regression shows that the thermoelastic slope, $m$, follows:

$$
m=6.0 \times 10^{6} * h-1.29
$$

where, $h$ is the individual layer thickness following linear fitting. The determined values of thermoelastic slope $\left(-1.21 \mathrm{MPa} /{ }^{\circ} \mathrm{C}\right.$ to $\left.-1.93 \mathrm{MPa} /{ }^{\circ} \mathrm{C}\right)$ are near the predicted value for $\mathrm{Cu} / \mathrm{Nb}$ of $-1.8 \mathrm{MPa} /{ }^{\circ} \mathrm{C}$. A linear fit was chosen due to the limited data available, which explained $82 \%$ of 
the variance. If the previously established approximation of thermoelastic slope (Eq. 1) [31] is combined with the relationship determined from the stress response of $\mathrm{Cu} / \mathrm{Nb} \mathrm{NMM}$ systems (Eq. 8) it is seen that the thermoelastic slope of NMM systems $(h<\approx 100 \mathrm{~nm})$ follows:

$$
m=k * h+\left(\frac{E_{f}}{v_{f}}\right) \Delta \alpha
$$

where $k$ is a system dependent constant found from the regression $\left(k_{C u / N b}: 6.0 \times 10^{6} \mathrm{MPa} / \mathrm{m}^{\circ} \mathrm{C}\right), h$ is the individual layer thickness (in meters), $E_{f}$ is the film elastic modulus, $v_{f}$ is the Poisson's ratio of the film, and $\Delta \alpha$ is the CTE mismatch in between the composite film system and substrate. However, it is suggested that this approach be applied to additional layer thicknesses of different NMM systems to better understand the relationship between layer thickness and thermoelastic slope. This dependence was not identified by Windt [30] or Gram et al. [36], probably due to the narrow range of layer thicknesses examined in those previous studies. Presently, almost two orders of magnitude in layer thickness were examined in comparison to Windt's examination of 1 to $5 \mathrm{~nm}$ individual layered systems [30] or $11 \mathrm{~nm}$ and $21 \mathrm{~nm} \mathrm{Cu} / \mathrm{Ni}$ by Gram et al. [36]. It is noted that there are other considerable structural differences between the $\mathrm{Cu} / \mathrm{Nb} \mathrm{NMM}$ systems examined in the present study and the $\mathrm{Cu} / \mathrm{Ni}$ examined by Gram et al. [36] and $\mathrm{Mo} / \mathrm{Si}$ examined by Windt [30] including interfacial coherency (incoherent for $\mathrm{Cu} / \mathrm{Nb}$ and nearly coherent for $\mathrm{Cu} / \mathrm{Ni}$ ) and elastic modulus mismatch. The impact of elastic modulus can be seen in the initial approximation of thermoelastic slope (Eq. 1) where greater values result in larger stresses [31]. Further, the interfacial coherency is likely to impact the development of the interfacial stresses that have been attributed to the change in layer thickness, but the full impact is not yet known. 


\subsection{Influence of multiple cycles on thermal stresses in NMM systems}

Testing consisting of three successive thermal cycles were used to examine the stress response of NMMs after initial deposition defects occurred [20]. It was observed that for all samples, the initial heating segment closely matched the single cycle tests presented in the previous section (3.3). On subsequent cycles, the $20 \mathrm{~nm} \mathrm{Cu} / \mathrm{Nb} \mathrm{NMM}$ system follows a cyclical progression, similar to what was measured for the initial cooling segment (Fig. 8). Above 200 ${ }^{\circ} \mathrm{C}$, the stress progression is linear. However, at lower temperatures non-linearity is observed, as determined by deviations from a linear fit.

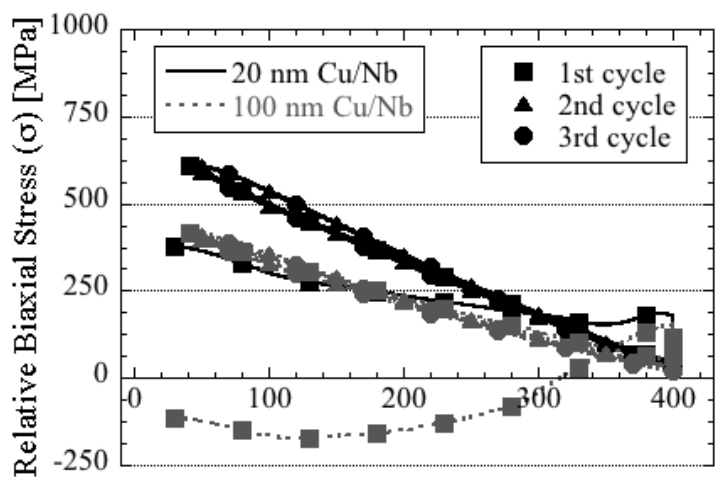

Stage Temperature $(\mathrm{T})\left[{ }^{\circ} \mathrm{C}\right]$

Fig. 8. Development of stress in 20 and $100 \mathrm{~nm} \mathrm{Cu} / \mathrm{Nb}$ NMM films upon three heating cycles to $400{ }^{\circ} \mathrm{C}$ at $10{ }^{\circ} \mathrm{C} / \mathrm{min}$. The inflection changes noted on the initial heating are absent in subsequent heating cycles. The hysteresis observed is largely consistent with those noted in the monolithic systems. At lower temperatures $\left(<200{ }^{\circ} \mathrm{C}\right)$ non-linear behavior is observed for the $20 \mathrm{~nm}$ system.

Linearity on subsequent cycles is also noted for the $100 \mathrm{~nm} \mathrm{Cu} / \mathrm{Nb}$ system (Fig. 8) and the other geometries examined $(20 \mathrm{~nm} \mathrm{Nb} / \mathrm{Cu}$ and $100 \mathrm{~nm} \mathrm{Nb} / \mathrm{Cu})$. When compared with the results from monolithic systems (Section 3.2), it is observed that, much like the initial cycle, the hysteresis is comparable with monolithic Nb films. These hystereses, although small, can be repeatedly observed as these stress profiles were measured two to three times for each condition. The deviations between stress on heating and cooling for $\mathrm{Cu}$ films above $100{ }^{\circ} \mathrm{C}$ (Fig. 4) are 
For Submission to Materials Science and Engineering A

absent in NMM systems. However, the continued development of larger tensile stresses in $\mathrm{Nb}$ films (Fig. 4) during the second and third isothermal hold at $400{ }^{\circ} \mathrm{C}$ are also notably absent from the NMM systems.

These results point to an important aspect, stress related system evolution is going to likely occur during the first thermal cycle. On subsequent cycles, the stress is traveling close to the path the sample followed on the initial cooling segment. If the stresses observed during the first cycle are insufficient to initiate degradation it is not likely that it will occur on following cycles.

\subsection{Comparison of curvature stress with XRD stress}

From in-situ heated XRD examination, it is observed that an older $20 \mathrm{~nm} \mathrm{Cu} / \mathrm{Nb} \mathrm{NMM}$ system exhibits very distinct stress behavior for the $\mathrm{Cu}$ and $\mathrm{Nb}$ components (Fig. 9). Upon heating, the stresses measured in the $\mathrm{Nb}$ layers remain constant until above $175{ }^{\circ} \mathrm{C}$, after which point they greatly increase. The stresses in the $\mathrm{Nb}$ layers then persist throughout the duration of the test. Contrastingly, the stresses measured in the $\mathrm{Cu}$ layers do not show this drastic change; on heating there are initial drops in stresses up until $175^{\circ} \mathrm{C}$ at which point the stresses increase again to a moderate value. On cooling, the stresses in the $\mathrm{Cu}$ layers increase relatively linearly. These stresses are consistent with a tensile stress in the film and a compressive stress in the substrate as should be expected from the CTE mismatch, however the absolute stress values are dependent on an accurate stress-free initial lattice parameter [36]. 


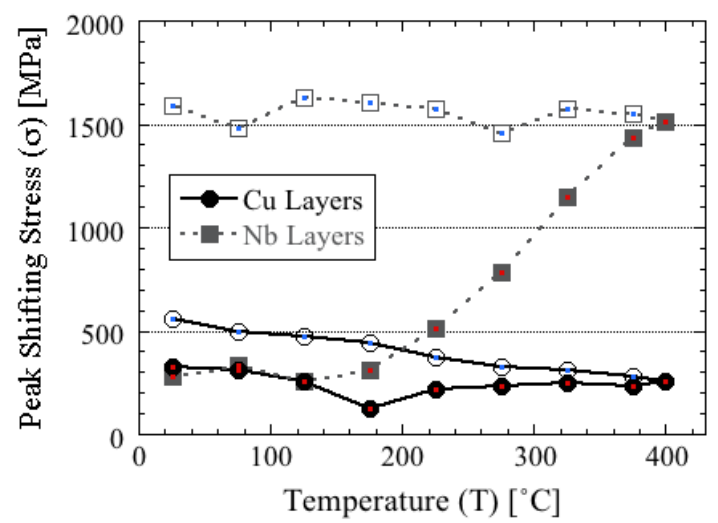

Fig. 9. Development of stresses in $20 \mathrm{~nm} \mathrm{Cu/Nb} \mathrm{NMM}$ system as calculated from measured lattice strain by in-plane XRD showing similar progression to what was observed for monolithic films by changes in curvature. In this case, stress is approximated using changes in peak position of primary $\mathrm{Cu}$ and $\mathrm{Nb}$ orientations as a measure of lattice strain. Closed red markers indicate heating, open blue markers indicate cooling, markers indicate where measurements were taken and the connecting lines are to guide the eye.

The stress behavior in the NMM system appears to show the same trends as were measured in the monolithic films by substrate curvature (Fig. 3). This is an important distinction: the stress measured in the individual layers of a composite system is consistent with the stress behavior of a similar single component under similar conditions. These results show similar trends to those seen in the $\mathrm{Cu} / \mathrm{Ni} \mathrm{NMM}$ systems examined by Gram et al. [36]. However, it is noted that the $\mathrm{Nb}$ response seen in the present study (Fig. 9) is dissimilar from the Ni stress response seen by Gram et al. [36], this is contrasted with the response expected of monolithic BCC metals seen in the literature [30]. Notably absent from the XRD measurements (Fig. 9) is the peak observed for the NMM systems $\left(350{ }^{\circ} \mathrm{C}\right.$ to $400{ }^{\circ} \mathrm{C}$, Fig. 6$)$.

Comparing the stress measurements from substrate curvature measurements and from XRD give two different responses: the composite stress and a phase specific approximation of stress. Bearing in mind the implications of residual stress, both values can be important design considerations depending on the application. If the NMM system is treated as a single 
For Submission to Materials Science and Engineering A

component (e.g. overall coating behavior) the curvature measurement is of greater interest. However, in understanding the behavior in a single layer (e.g. dislocation motion), then measuring the stress on a local level with XRD would be more pertinent.

\subsection{Post-heating confirmation of structure and properties}

Substantial grain growth was observed for monolithic $\mathrm{Cu}$ due to heating, as determined by AFM. The initial $\mathrm{Cu}$ grain size was $83 \mathrm{~nm}$, which grew to $140 \mathrm{~nm}$ after heating. These measurements were also corroborated with EBSD measurements (grain size: $160 \pm 30 \mathrm{~nm}$ ). However, grain growth was not observed for the monolithic $\mathrm{Nb}$ film. Both before and after heating, the grain sizes were approximately $60 \mathrm{~nm}$. This is to be expected considering the melting temperatures of $\mathrm{Cu}$ and $\mathrm{Nb}, 1085{ }^{\circ} \mathrm{C}(1358 \mathrm{~K})$ and $2469{ }^{\circ} \mathrm{C}(2742 \mathrm{~K})$ respectively. The temperature associated with grain growth in bulk metals is often assumed to be approximately half of the melting temperature $\left[406{ }^{\circ} \mathrm{C}(679 \mathrm{~K})\right.$ and $1098{ }^{\circ} \mathrm{C}(1371 \mathrm{~K})$ for $\mathrm{Cu}$ and $\mathrm{Nb}$, respectively].

Appreciable grain growth in the $\mathrm{Cu}$ layer for the NMM systems examined was also observed. Initial grain sizes of the uppermost layers in both 20 and $100 \mathrm{~nm}$ architectures were approximately $42 \mathrm{~nm}$. After heating the grains grew, but still remained sub-150 nm (100 $\pm 6 \mathrm{~nm}$ and $127 \pm 9 \mathrm{~nm}$ for $20 \mathrm{~nm}$ and $100 \mathrm{~nm} \mathrm{Nb} / \mathrm{Cu}$ architectures, respectively). Previous reports indicate that the NMM structure allows for minimal grain growth during heating resulting in grains remaining largely nanocrystalline [9]. These measurements were taken from AFM scans of the uppermost layer of the NMM systems, which in the case of $\mathrm{Nb} / \mathrm{Cu}$ is $\mathrm{Cu}$. AFM measurements of the film surface could be impacted by the formation of a surface oxide, but it is estimated that substantial oxidation was not observed, as the surfaces remained highly reflective, 
copper colored, and XRD did not reveal the formation of additional peaks pertaining to an oxide phase (Fig. 10).

XRD of the $\mathrm{Nb} / \mathrm{Cu} \mathrm{NMM}$ systems shows minimal changes to the observed phases (Fig. 10). The primary peaks observed following deposition persist with similar relative intensities to the previous measurements. Negligible changes in XRD peaks should be expected as $\mathrm{Cu}$ and $\mathrm{Nb}$ are completely insoluble in one another [28]; no intermetallic compounds should be formed. The $\mathrm{XRD}$ results serve to indicate that there was minimal impact of the thermal cycling seen herein on the observable structure of the NMM systems. For the conditions examined in this study, softening was not observed, as the authors have previously seen [9]. Rather, an increase in hardness for all systems was observed (e.g. $\mathrm{H}_{\text {ini }}$ : $4.7 \pm 0.2 \mathrm{GPa}$ and $\mathrm{H}_{\text {final }}$ : $5.8 \pm 0.2 \mathrm{GPa}$ for 20 $\mathrm{nm} \mathrm{Nb} / \mathrm{Cu}$ ), which is consistent with other researchers' observations [23,24,49,50].

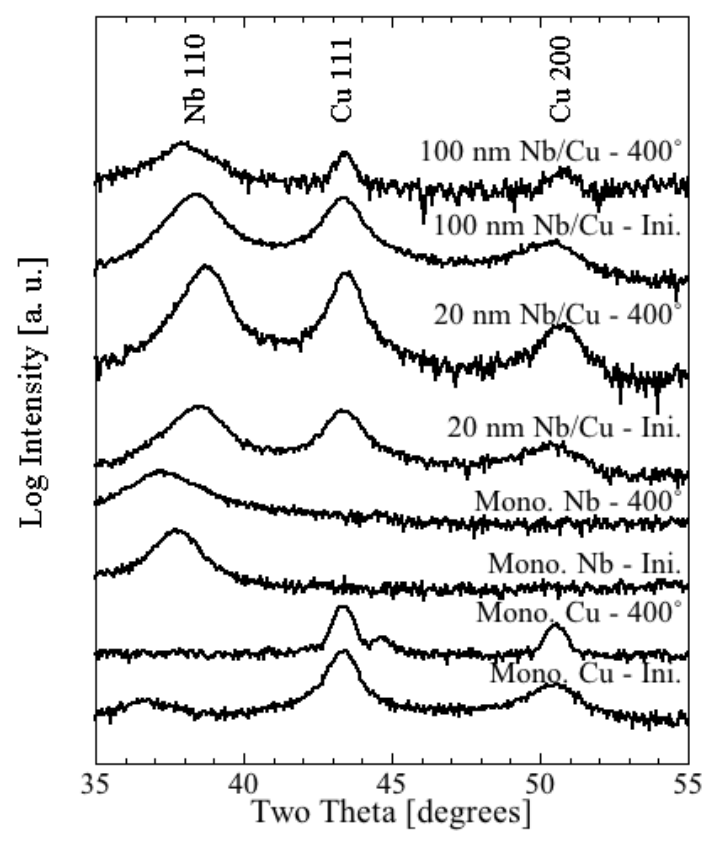

Fig. 10. XRD patterns of film systems for this study before and after heating to $400{ }^{\circ} \mathrm{C}$ including monolithic films and NMM architectures. Diffraction peaks indicate primary orientations of $\mathrm{Cu}$ and $\mathrm{Nb}$ components. The $\mathrm{Nb}$ peak shifts significantly indicative of large tensile stresses in the film. Minimal differences are observed between initial and final states indicating negligible structural changes in the films due to heating. 


\section{Conclusions}

To clarify the development of residual stresses in $\mathrm{NMM} \mathrm{Cu/Nb}$ during thermal cycling, changes in substrate curvature were measured using an in-situ measurement system. Through the examination of residual stresses developed during thermal cycling of $\mathrm{Cu} / \mathrm{Nb} \mathrm{NMM}$ systems, it has been determined that the $\mathrm{Nb}$ component largely controls the stress of the system. Using complimentary stress measurement techniques (substrate curvature and XRD) the differences between composite and phase specific stresses have been identified. The stresses developed in $\mathrm{Cu}$ and $\mathrm{Nb}$ layers as measured by XRD follow similar trends to those in monolithic systems measured with wafer curvature. This is contrasted to the hysteresis observed as measured by substrate curvature, which can be considered a composite stress for the multicomponent system. By identifying deviations between the composite stress (substrate curvature) and phase stresses (XRD), it is hypothesized that the decreasing yield strength at elevated temperatures of $\mathrm{Cu}$ and high stress of $\mathrm{Nb}$ layers may have acted together to limit the stress development above $300{ }^{\circ} \mathrm{C}$.

The layer thickness affects the stress progression during thermal cycling. It was observed that there is a distinct change in the thermoelastic slope of the stress developed on cooling for the different layer thicknesses, highlighting the importance of interfacial stresses in these nanostructured materials. Stress in these NMM systems should not be treated as a rule of mixtures considering only the volume fraction of the constituents. The interfacial density is also an important consideration. Initial stress will dictate the stress progression during the preliminary heating, but after that point the stress response on cooling and subsequent cycles is equivalent. 
For Submission to Materials Science and Engineering A

In this study, softening of the NMM structures was not observed as has been previously identified for $\mathrm{Cu} / \mathrm{Nb} \mathrm{NMM}$ systems still bound to their substrate [9]. However, the uniformity of hardness after thermal cycling is consistent with other researcher's observations on other NMM systems $[23,49,50]$. It is still supposed that there is a link between the residual stress of these systems and their thermal stability [11].

\section{Acknowledgments}

In-situ heated XRD measurements were performed at the Center for Nanophase Materials Sciences, which is a DOE Office of Science User Facility. The authors wish to acknowledge the assistance of Dr. W. Heinz (K-AI GmbH), Dr. J. E. Harriss (Clemson University), Dr. L. V. Saraf (Clemson University), Mr. B. M. Schultz (Clemson University), Dipl.-Ing. S. P. Bigl (Montanuniversitaet Leoben), and Dr. T. Schöberl (Erich Schmid Institute) for their helpful discussions and guidance. This work was partially supported by funding from the Austrian Marshall Plan Foundation. 
For Submission to Materials Science and Engineering A

\section{References}

[1] A. Misra, in:, R.H.J. Hannick Hill, A. J. (Ed.), Nanostructure Control Mater., Woodhead Publishing, Cambridge, England, 2006, pp. 146-176.

[2] A. Misra, J.P. Hirth, R.G. Hoagland, Acta Mater. 53 (2005) 4817.

[3] N.A. Mara, I.J. Beyerlein, J. Mater. Sci. 49 (2014) 6497.

[4] I.J. Beyerlein, A. Caro, M.J. Demkowicz, N.A. Mara, A. Misra, B.P.P. Uberuaga, Mater. Today 16 (2013) 443.

[5] W. Han, M.J. Demkowicz, N.A. Mara, E. Fu, S. Sinha, A.D. Rollett, Y. Wang, J.S. Carpenter, I.J. Beyerlein, A. Misra, Adv. Mater. (2013) 6975.

[6] A. Misra, M.J. Demkowicz, X. Zhang, R.G. Hoagland, JOM 59 (2007) 62.

[7] S. Wen, R. Zong, F. Zeng, Y. Gao, F. Pan, Wear 265 (2008) 1808.

[8] A. Haseeb, J. Celis, J. Roos, Thin Solid Films 444 (2003) 199.

[9] D.R. Economy, B.M. Schultz, M.S. Kennedy, J. Mater. Sci. 47 (2012) 6986.

[10] D. Josell, F. Spaepen, MRS Bull. 24 (1999) 39.

[11] D. Josell, W. Carter, J. Bonevich, Nanostructured Mater. 12 (1999) 387.

[12] A. Lewis, D. Josell, T. Weihs, Scr. Mater. 48 (2003) 1079.

[13] R.W. Balluffi, S. Allen, W.C. Carter, Kinetics of Materials, John Wiley \& Sons, 2005.

[14] J.P. Hirth, Scr. Mater. 50 (2004) 793.

[15] A.C. Fischer-Cripps, Nanoindentation, Springer, New York, 2004. 


\section{For Submission to Materials Science and Engineering A}

[16] L. Ling, S. Long, Z. Ma, X. Liang, J. Mater. Sci. Technol. 26 (2010) 1001.

[17] J. Weertman, J. Weertman, Elementary Dislocation Theory, Macmillan, 1966.

[18] C.C. Montarou, T.K. Gaylord, A.I. Dachevski, Opt. Commun. 265 (2006) 29.

[19] M. Ohring, Materials Science of Thin Films, 2nd ed., Academic Press, San Diego, CA, 2002.

[20] J.J. Toomey, S. Hymes, S.P. Murarka, Appl. Phys. Lett. 66 (1995) 2074.

[21] C.C. Chama, J.J. Vlassak, W.O. Soboyejo, Mater. Sci. Eng. A 532 (2012) 414.

[22] A.A. Taylor, S.H. Oh, G. Dehm, J. Mater. Sci. 45 (2010) 3874.

[23] S. Zheng, I.J. Beyerlein, J.S. Carpenter, K. Kang, J. Wang, W. Han, N.A. Mara, Nat. Commun. 4 (2013) 1696.

[24] A. Misra, R.G. Hoagland, J. Mater. Res. 20 (2005) 2046.

[25] W.Z. Han, N.A. Mara, Y.Q. Wang, A. Misra, M.J. Demkowicz, J. Nucl. Mater. 452 (2014) 57.

[26] K. Hattar, A. Misra, M. Dosanjh, J. Eng. Mater. Technol. 134 (2012) 21014.

[27] N. Li, J. Wang, A. Misra, J.Y. Huang, Microsc. Microanal. 18 (2012) 1155.

[28] L. Kaufman, H. Nesor, Calphad 2 (1978) 81.

[29] C.-H. Hsueh, J. Appl. Phys. 91 (2002) 9652.

[30] D.L. Windt, J. Vac. Sci. Technol. A Vacuum, Surfaces, Film. 18 (2000) 980.

[31] R.-M. Keller, S.P. Baker, E. Arzt, Acta Mater. 47 (1999) 415.

[32] R. Vinci, E. Zielinski, J. Bravman, Thin Solid Films 262 (1995) 142. 


\section{For Submission to Materials Science and Engineering A}

[33] Y.S. Touloukian, R.K. Kirby, R.E. Taylor, P.D. Desai, THERMOPHYSICAL, E.P.I.A.C.L. IN., Thermophysical Properties of Matter - the TPRC Data Series. Volume 12. Thermal Expansion Metallic Elements and Alloys, Defense Technical Information Center, 1975.

[34] Y.S. Touloukian, R.K. Kirby, E.R. Taylor, T.Y.R. Lee, THERMOPHYSICAL, E.P.I.A.C.L. IN., Thermophysical Properties of Matter - the TPRC Data Series. Volume 13. Thermal Expansion - Nonmetallic Solids, Defense Technical Information Center, 1977.

[35] J.-M. Zhang, Y. Zhang, K.-W. Xu, V. Ji, J. Phys. Chem. Solids 68 (2007) 503.

[36] M.D. Gram, J.S. Carpenter, E.A. Payzant, A. Misra, P.M. Anderson, Mater. Res. Lett. 1 (2013) 233.

[37] V. Ramaswamy, W.D. Nix, B.M. Clemens, Scr. Mater. 50 (2004) 711.

[38] M.A. Hopcroft, W.D. Nix, T.W. Kenny, Microelectromechanical Syst. J. 19 (2010) 229.

[39] G. Stoney, Proc. R. Soc. London. Ser. A 82 (1909) 172.

[40] W.C. Oliver, G.M. Pharr, J. Mater. Res. 7 (1992) 1564.

[41] E. Eiper, J. Keckes, K.J. Martinschitz, I. Zizak, M. Cabié, G. Dehm, Acta Mater. 55 (2007) 1941.

[42] O. Kraft, M. Hommel, E. Arzt, Mater. Sci. Eng. A 288 (2000) 209.

[43] Y. Talmor, E. Walker, S. Steinemann, Solid State Commun. 23 (1977) 649.

[44] Y.A. Chang, J. Appl. Phys. 37 (1966) 3567.

[45] D. Beegan, S. Chowdhury, M.T. Laugier, Surf. Coatings Technol. 201 (2007) 5804.

[46] L. Kommel, E. Kimmari, M. Saarna, M. Viljus, J. Mater. Sci. 48 (2013) 4723.

[47] K. Yu-Zhang, J.D. Embury, K. Han, A. Misra, Philos. Mag. 88 (2008) 2559. 


\section{For Submission to Materials Science and Engineering A}

[48] C.A. Schuh, C.E. Packard, A.C. Lund, J. Mater. Res. 21 (2006) 725.

[49] R.L. Schoeppner, N. Abdolrahim, I. Salehinia, H.M. Zbib, D.F. Bahr, Thin Solid Films 571 (2014) 247.

[50] N.A. Mara, A. Misra, R.G. Hoagland, A. V Sergueeva, T. Tamayo, P. Dickerson, A.K. Mukherjee, Mater. Sci. Eng. A 493 (2008) 274. 